\begin{tabular}{|c|c|c|c|c|c|}
\hline MUNIBE Antropologia-Arkeologia & $n^{\circ} 65$ & $269-288$ & DONOSTIA & 2014 & ISSN 1132-2217 • eISSN 2172-4555 \\
\hline
\end{tabular}

\title{
Simas, cavernas y pozos para ocultar cadáveres en la Guerra Civil española (1936-1939). Aportaciones desde la Antropología Forense
}

\author{
Bodies hidden in potholes, caves and wells in the Civil War (1936-1939). \\ Contributions of Forensic Anthropology
}

KEY WORDS: Mass graves, Civil War, Forensic Anthropology.

PALABRAS CLAVES: Fosas comunes, Guerra Civil, Antropología Forense.

GAKO-HITZAK: Hilobi komunak, Gerra Zibila, Auzitegiko Antropologia.

Francisco ETXEBERRIA(1), Fernando SERRULLA(2) y Lourdes HERRASTI(3)

\section{ABSTRACT}

Since 2000, numerous exhumations have taken place in Spain in response to a historical memory protest movement related to the Civil War and the Dictatorship of General Francisco Franco. It is estimated that over the last decade, 379 graves have been exhumed, from which 6,680 skeletons have been recovered and studied from a forensic perspective.

Thousands of victims of the Civil War (1936-1939) remain buried in common graves all over the country. However, in addition to graves dug in peripheral areas or cemeteries, artificial wells and natural shafts were also used to hide the evidence of bloody crimes. Such resources have been used throughout history in situations of conflict and they explain some of the finds that have been made: bodies hidden in places where it seemed impossible they could be found and, therefore, retrieved. However, advances in archaeological techniques in the field of Forensic Science have made it possible to recover these remains for analysis.

In particular, exhumations in wells and caves present further difficulties for archaeological techniques, so a specific methodology has been developed which is continuously being improved and adapted to each individual case. Furthermore, it has been shown that even when it is considered impossible to recover these remains, it is always possible to design specific techniques to enable excavations to be performed correctly.

This paper presents the results of these actions, cataloguing the places where exhumations have taken place and others where they are yet to be completed. Some of these cases were not investigated using appropriate methods as they did not involve professional archaeologists or forensic scientists.

Forensic archaeology and forensic anthropology play a vital role when faced with the challenge of performing excavations under rubble that has been deliberately dumped in order to conceal the crimes at the bottom of caves and wells.

\section{RESUMEN}

Son miles las víctimas de la Guerra Civil (1936-1939) que permanecen enterradas en fosas comunes repartidas por todo el territorio. Pero además de las fosas en zonas marginales o en cementerios, se emplearon también pozos artificiales y simas naturales para hacer desaparecer las evidencias de los crímenes cometidos. Este recurso ha sido utilizado a lo largo de toda la historia en situaciones de conflicto y explica algunos hallazgos que se han realizado: la ocultación de los cuerpos en espacios aparentemente imposibles para su localización y rescate posterior. Sin embargo, el avance en las técnicas arqueológicas implicadas en el ámbito de las Ciencias Forenses han posibilitado la adecuada recuperación de estos restos y su posterior análisis.

\section{LABURPENA}

Lurralde osoan sakabanaturik, Gerra Zibilaren milaka biktima dira hobi komunetan lurperatuta jarraitzen dutenak. Baina leku bazterretako edo hilerrietako hobiak ez ezik, putzu artifizialak eta leize naturalak ere erabili ziren egindako erailketen aztarnak desagerrarazteko. Baliabide hau historia osoan zehar erabili izan da gatazka-egoeretan, eta egin diren aurkikuntzetako batzuk azaltzen ditu: itxuraz eskuraezinak diren lekuetan gorpuak ezkutatzea, aurrerago horiek aurkitzea eta berreskuratzea ezinezkoa izan dadin. Hala ere, Auzitegi-Zientzien alorrean egin diren aurrerapenei esker, posible izan da mota horretako gorpuzkinak berreskuratzea eta jarraian aztertzea.

\footnotetext{
(1) Medicina Legal y Forense. Facultad de Medicina. Universidad del País Vasco UPV/EHU. Apartado 1599. 20014 Donostia - San Sebastián. paco.etxeberria@ehu.es

(2) Unidad de Antropología Forense. Instituto de Medicina Legal de Galicia. fernandoserrullarech@hotmail.com

(3) Departamento de Antropología Sociedad de Ciencias Aranzadi. Donostia-San Sebastián. antropologia@aranzadi-zientziak.org
} 


\section{1.- INTRODUCCIÓN}

En 1978, el Sr. Pere Plana Panyart del Grupo Espeleológico Edelweis publica el resultado del levantamiento del cadáver hallado en el "torcón de cueva Burgos" del término municipal de Contreras (Burgos). Se trataba del hallazgo casual de un esqueleto humano perteneciente a una persona mayor que se encontraba vestida y habría fallecido en época contemporánea (PLANA, 1978).

En realidad los restos, en fase de reducción esquelética, se encontraron al pie de la vertical del pozo de entrada de $27 \mathrm{~m}$ de esta cavidad natural.

La documentación generada, junto con las fichas de campo, un croquis o dibujo sobre la distribución de los restos y una adecuada descripción de lo allí encontrado, permite ahora comprender adecuadamente este hallazgo efectuado el día 18 de enero de 1976.

La metodología empleada fue la adecuada en su tiempo con fijación fotográfica y un ejemplo, temprano, de lo que pueden ser este tipo de investigaciones siempre complicadas por las características de estos lugares. Además, el caso fue investigado por la autoridad judicial con la participación de la Guardia Civil de Lerma (Burgos), sin que se lograra la identificación de este esqueleto.

¿Qué posibilidades hay de que este esqueleto perteneciera a una víctima de las represalias de la Guerra Civil entre 1936-1939?

Seguramente nunca lo sabremos, pero el hecho cierto es que existen numerosos lugares en los que se aprovecharon las cavernas y pozos para arrojar los cadáveres y ocultar los crímenes cometidos como una solución relativamente cómoda y de oportunidad para sus perpetradores.

Esta circunstancia es tan antigua como nueva ya que en la actualidad también se producen casos equivalentes. Así por ejemplo en la sima Bide Gorri de Azkoitia (Gipuzkoa) en donde se encontró un cadáver a $90 \mathrm{~m}$ de profundidad el año 2009, o en la cavidad del Alto del Viento entre Ronda y El Burgo donde se localizó un esqueleto masculino el año 2011 con una data de 30 o 40 años o en la cueva de Pedrosa de Valdeporres (Burgos) donde fue ocultado otro cadáver a 15 m de profundidad en año 2012. Junto a lo anterior aún son más frecuentes los pozos artificiales con casos recientes como en Elche (Alicante) con un cuerpo recuperado en 2012 y Almonaster (Huelva) de donde se extrajeron los restos de una mujer y su hijo de cinco años en 2011 que habían sido asesinados 18 años antes, por poner algunos ejemplos. Finalizando el año 2014, el grupo de espeleología Satorrak descubre un cadáver reciente en la sima de Gaztelu (Navarra) que es objeto de investigación por parte del Juzgado de Instrucción n 4 de Pamplona.

\section{2.- SIMAS, CAVERNAS Y POZOS CON RESTOS HUMANOS DE LA GUERRA CIVIL}

A partir del año 2000 se ha suscitado un interés creciente en materia de memoria histórica ${ }^{1}$ relacionada con las víctimas de le Guerra Civil y del franquismo. Hasta el presente (septiembre de 2014) se han exhumado 379 fosas comunes y recuperado 6680 esqueletos $^{2}$ y algunos de ellos han sido localizados en cavidades naturales, como cuevas y simas, o en pozos artificiales para extracción de agua, así como minas abandonadas (Fig. 1).

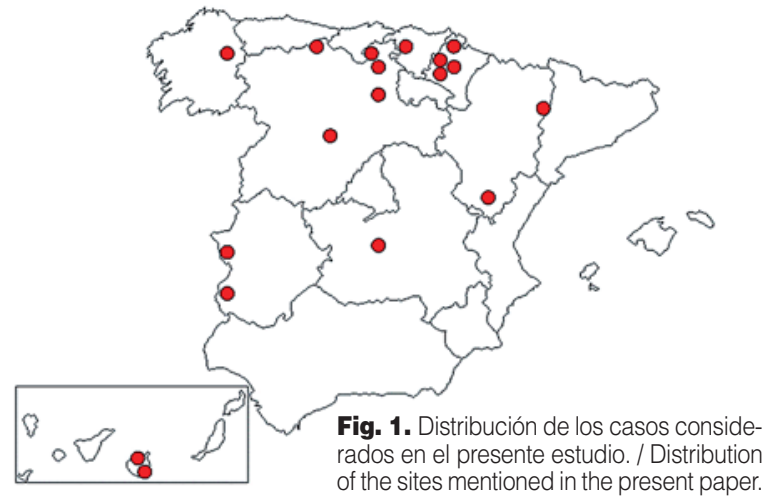

\begin{tabular}{|l|c|c|c|}
\hline NATURALES: & Término & Provincia & N$^{\circ}$ de restos \\
\hline Sima El Grajero & & & \\
\hline Sima de Otsoportillo & Lario & León & 13 \\
\hline Sima de Kurtzetxiki-Bedoña & Sierra de Urbasa & Navarra & $?$ \\
\hline Sima volcánica de Jinamar & Arrasate & Gipuzkoa & 2 \\
\hline Sima de Kristoleze & Lizarraga-Andía & Gran Canaria & $?$ \\
\hline Sima del Raso de Urbasa & Sierra de Urbasa & Navarra & $?$ \\
\hline Sima de Ardaitz & Valle de Erro & Navarra & 2 \\
\hline Simas de Dolencias & Sotoscueva & Burgos & $?$ \\
\hline Sima de Gaztelu & Gaztelu & Navarra & $?$ \\
\hline Sima Torca Palomera & Mozuelos de Sedano & Burgos & $?$ \\
\hline Cova Arcoia & Sierra del Caurel & Lugo & 2 \\
\hline Cueva de Humarraña & Loma de Montija & Burgos & 2 \\
\hline ARTIFICIALES: & & & \\
\hline Pozos de Caude & Llanos de Caudé & Teruel & $?$ \\
\hline Pozo Ventafarinas & Tamarite de Litera & Huesca & $?$ \\
\hline Pozo del Llano de las Brujas & Arucas & Gran Canaria & 24 \\
\hline Pozo-mina de Valdihuelo & Alburquerque-San Vicente & Badajoz & $15-17$ \\
\hline Pozo-mina de Las Cabezuelas & Camuñas & Toledo & +50 \\
\hline Pozo-mina El Salamanco Chico & La Parra & Badajoz & +2 \\
\hline Calero de Covarrubias & Covarrubias & Burgos & 8 \\
\hline Bodega Peña Tejada & Medina del Campo & Valladolid & $?$ \\
\hline
\end{tabular}

Tabla 1: Relación de casos analizados, pozos y cavernas en donde se arrojaron cadáveres durante la Guerra Civil. No se añade la llamada Sima del Republicano en Grazalema (Cádiz), por existir dudas con respecto a la veracidad de que hubiera sido empleada para hacer desaparecer a personas durante la Guerra Civil. / Table 1: List of the sites, shafts and caves where bodies were thrown during the Civil War. The Sima del Republicano in Grazalema (Cádiz) has not been added because of the doubts about it being used to make people disappear during the Civil War.

${ }^{1}$ El término de memoria histórica comienza a emplearse a partir de la investigación en la sima de Lario (León) el año 1998. El trabajo más completo desde la perspectiva forense puede consultarse en: http://www.agmf.es/boletines/boletin18.pdf

${ }^{2}$ Con el apoyo del Ministerio de la Presidencia, la Sociedad de Ciencias Aranzadi lleva a cabo desde 2009 el proyecto para realizar una base de datos con información integral de las fosas comunes exhumadas de la guerra civil, bajo la dirección de Fco. Etxeberria Gabilondo. Asimismo se puede consultar esta relación de fosas exhumadas en el proyecto "Las políticas de la memoria en la España contemporánea: Análisis del impacto de las exhumaciones de la Guerra Civil en los primeros años del Siglo XXI", referencia CSO2009-09681 (MICINN) bajo la dirección del Dr. Francisco Ferrándiz del Consejo Superior de Investigaciones Científicas. Ver: http://politicasdelamemoria.org/ 


\section{SIMA EL GRAJERO (Lario, León)}

Situada en los montes de Polvoredo y Lario en León. Se trata de una cavidad natural donde fueron arrojados un número indeterminado de personas a unos $20 \mathrm{~m}$ de profundidad. En concreto, el 13 de noviembre de 1937, fueron un total de 13 personas. Dependiendo de las fuentes, se interpreta que en esta cavidad puede haber entre 40 y 150 personas.

El 7 de noviembre de 1998 la prensa local de León se hizo eco de la aparición de restos en la sima pertenecientes a personas ejecutadas durante la Guerra Civil y la represión franquista. Efectivos del Grupo de Rescate e Intervención en Montaña de la Guardia Civil con sede en Sabero descubren varios esqueletos. El caso fue puesto en conocimiento del Juzgado de Primera Instancia e Instrucción de Cistierna que ordenó el levantamiento de los huesos y la práctica de diligencias ${ }^{3}$.

Los análisis se realizaron en el Instituto Nacional de Toxicología que estableció en 13 el número mínimo de individuos. Por decisión de los familiares los restos fueron finalmente inhumados en un nicho del cementerio de Lario el 24 de febrero de 2000.

En 2001 el acceso a la cavidad fue sellado por la Asociación Pozo Grajero. Todos los años esta asociación realiza un homenaje en el lugar donde se encuentra la sima.

El completo trabajo publicado por esta asociación el año 2008 bajo el título "La memoria del Grajero" recoge un esquema de la cavidad con fotografías de algunos restos, así como abundantes testimonios de los hechos ocurridos.

\section{SIMA DE OTSOPORTILLO}

\section{(Sierra de Urbasa, Navarra)}

Situada en la Sierra de Urbasa. Coordenadas UTM: X 569.699, Y 4.745.048. Se trata de una cavidad natural con entrada en forma vertical en donde fueron arrojados un número indeterminado de cuerpos ${ }^{4}$. Dicha cavidad ha sido visitada periódicamente desde el año 1980 y los restos permanecen dispersos en la galería siendo probable que se hayan extraído algunos huesos, aunque en la actualidad la entrada está cerrada con una verja.

Durante el mes septiembre y desde el año 1980, la Asociación de Familiares de fusilados de Sakana y el ayuntamiento de Etxarri Aranaz celebran un homenaje a las víctimas. De hecho, existe un monumento junto a la boca de acceso realizado por el escultor José Ramón Anda.

\section{SIMA DE KURTZETXIKI-BEDOÑA (Arrasate, Gipuzkoa)}

Fruto de las investigaciones que realiza en la década de los años 70 el Grupo de Espeleología Besaide de Arrasate, se localiza un cráneo humano en el interior de una sima en Kurtzetxiki en el barrio de Bedoña de Arrasate (Gipuzkoa). Por testimonios relatados en ese tiempo, se sabe que los restos pertenecen al tiempo de la Guerra Civil de 1936. Posteriormente este cráneo es depositado en el Departamento de Antropología de Sociedad de Ciencias Aranzadi ya que entre 1980 y 1990 miembros de este departamento realizan el estudio sistemático de todas las cavidades con restos humanos del País Vasco.

Sobre el año 1988, el mismo Grupo de Espeleología recupera otro cráneo humano en la dicha cavidad, así como restos correspondientes a calzado (una bota de cuero).

En fecha 23-09-2002, por consejo del Alcalde de Arrasate, miembros de Grupo de Espeleología Besaibe realizan otra visita a la cavidad acompañados por el Sr. Juan Ramón Garai, Concejal del mismo ayuntamiento ${ }^{5}$.

El lugar se localiza en el término municipal de Arrasate y al mismo se accede desde la carretera que de esa localidad asciende al barrio de Bedoña, en el paraje denominado Kurtzetxiki. Las coordenadas U.T.M. son las siguientes: $X$ 541.960, Y 4.767.193, Z 400.

En estas condiciones, se organiza un equipo de trabajo y se acuerda realizar una exploración de la cavidad y recuperar los restos el día 6-10-20026. Tras equipar la entrada a la sima que tiene un salto vertical de $6 \mathrm{~m}$, descienden varios miembros del Departamento de Espeleología y realizan una instalación con luz eléctrica alimentada mediante un generador en el exterior. Posteriormente realizamos una primera inspección del suelo de la galería que tiene una fuerte pendiente de unos $20 \mathrm{~m}$ de longitud (Fig. 2). Al pie de la vertical de entrada el suelo es de tierra muy orgánica con barro y elementos vegetales arrojados desde el exterior. La galería desciende linealmente hasta el fondo en el que predominan elementos rocosos de todos los tamaños. En esta primera inspección localizamos numerosos restos esqueléticos de todo tipo y entre ellos la concentración de unos pertenecientes al Individuo 1 que permanecen en la parte media de la galería.

De este modo, decidimos recoger todos los huesos comenzando desde el fondo de la cavidad y recorriendo toda la galería sin apenas remoción de las piedras. En un trabajo coordinado con el exterior, los retos son extraídos en cajas de plástico mediante una polea y acumulados en bolsas.

\footnotetext{
${ }^{3}$ A partir de estos hallazgos comienza a acuñarse el término de Memoria Histórica aplicado al estudio y reivindicación de las víctimas de la Guerra Civil y del franquismo.

${ }^{4}$ Algunos autores señalan que pueden ser dos centenares de cuerpos los arrojados a esta sima y otras cavidades (Basanziturri y Ordoz) de la sierra de Urbasa citando al historiador navarro José $M^{a}$ Jimeno Jurio (EGAÑA, 2009).

${ }^{5}$ En escrito remitido por la Alcaldía de Arrasate fechado el 1-10-2002 se solicita la intervención de la Sociedad de Ciencias Aranzadi para investigar los restos humanos. Por su parte, desde la Sociedad de Ciencias Aranzadi se acuerda designar la dirección de la investigación a Fco. Etxeberria Gabilondo y enviar un escrito de carácter informativo al Dpto. de Cultura de la Diputación Foral de Gipuzkoa, así como a la Comisaría de la Ertzaintza de Arrasate.

${ }^{6}$ Intervino un equipo constituido de la siguiente manera: Dirección científica, Fco. Etxeberria Gabilondo. Edelweis Aldasoro, Nagore Amodarain, Ainara Lizaso e Izaskun Emazabel (estudiantes de Medicina de la Universidad del País Vasco), Juanjo Iglesias, Joseba Iglesias y José Mari Expósito (del grupo de Espelelogía Besaibe), Juan Ramón Garai (Concejal del Ayuntamiento de Arrasate), Beñat Ibaieta, Rafael Zubiria, Inasio Arregi, Imanol Goikoetxea y Eva Piélago (Sección de Espeleología de la Sociedad de Ciencias Aranzadi).
} 
En un segundo tiempo, realizamos un nuevo barrido comenzando nuevamente desde el fondo de la sima removiendo las piedras que las arrojamos a la cota más inferior. Así, localizamos nuevamente otros restos esqueléticos que se recogen de igual modo. Al remover las piedras localizamos un fragmento de obús de $26 \mathrm{~cm}$ de largo y $14 \mathrm{~cm}$ de ancho con un espesor máximo de $17 \mathrm{~mm}$, así como restos de cuero pertenecientes a calzado equivalente al encontrado con anterioridad por el Grupo de Espeleología Besaide. Finalmente, prestamos más atención al lugar en el que se concentran los restos pertenecientes al Individuo 1 que, en parte, se encuentra semienterrado y oculto por el barro y restos pertenecientes a fauna doméstica.

Los restos esqueléticos recuperados en la sima de Kurtxetxiki pertenecen a dos individuos masculinos desigualmente representados ${ }^{7}$.

\section{Descripción antropológica Individuo 1 de Kurtzetxiki:}

Se encuentra depositado en posición decúbito supino con la extremidad superior izquierda cruzada bajo la cabeza en la superficie de la galería y parcialmente cubierto por desperdicios y tierra que se ha debido arrojar desde la boca de la cavidad a lo largo de los últimos años. El grado de conservación del esqueleto es bueno si bien se encuentra incompleto. Individuo masculino de una edad adulta madura escasamente superior a los 40 años. Existe un predominio de las proporciones del lado izquierdo, por lo que pudiera ser zurdo. La estatura, calculada la media de todos los parámetros y siguiendo a los autores al uso, sería de $170 \mathrm{~cm}$.

Presenta diversas lesiones que son compatibles con el paso de proyectiles de arma de fuego. En primer lugar destaca una perforación acanalada en la región posterior del parietal derecho de $27 \mathrm{~mm}$ de diámetro mayor por $9 \mathrm{~mm}$ de diámetro menor en forma de tronco de cono con mayor pérdida de hueso en la tabla interna y que se corresponde con el impacto tangencial de un proyectil que habría penetrado en la cavidad craneal oblicuamente.

Igualmente, el fragmento mandibular conservado presenta una fractura con arrancamiento de hueso y fractura de piezas dentarias en la rama del lado izquierdo ocasionada por un proyectil con una dirección de delante atrás y de derecha a izquierda, que debió de fracturar la parte del maxilar superior del lado derecho que se encuentra ausente.

Finalmente, la $9^{\circ}$ vértebra dorsal presenta una perforación con pérdida de hueso en la zona del pedículo derecho y apófisis transversa del mismo lado con un diámetro de entre 7 a $8 \mathrm{~mm}$, que corresponde al paso de un proyectil de arma de fuego con una dirección de delante atrás y de derecha a izquierda. Dicha vértebra se encuentra rasgada longitudinalmente en la apófisis transversa.
En definitiva, los tres impactos de arma de fuego habrían alcanzado al individuo por delante y desde el lado derecho con una trayectoria ligeramente descendente.

\section{Descripción antropológica Individuo 2 de Kurtzetxiki:}

Se encuentra disperso en la parte más inferior de la galería y resulta totalmente imposible precisar su posición y ubicación exacta ya que los restos esqueléticos son escasos y su conservación muy incompleta. A este individuo asociamos los restos de una bota izquierda de cuero con suela de tachuelas característica de la época.

Individuo masculino de edad subadulta, es decir, con una edad inferior a los 20 años que se confirma por la falta de fusión de metacarpianos y metatarsianos. No resulta posible inferir la estatura por la falta de huesos largos de las extremidades inferiores. Tampoco resulta posible interpretar la causa de su muerte ya que se encuentra muy incompleto y en los escasos restos conservados no se evidencian lesiones.
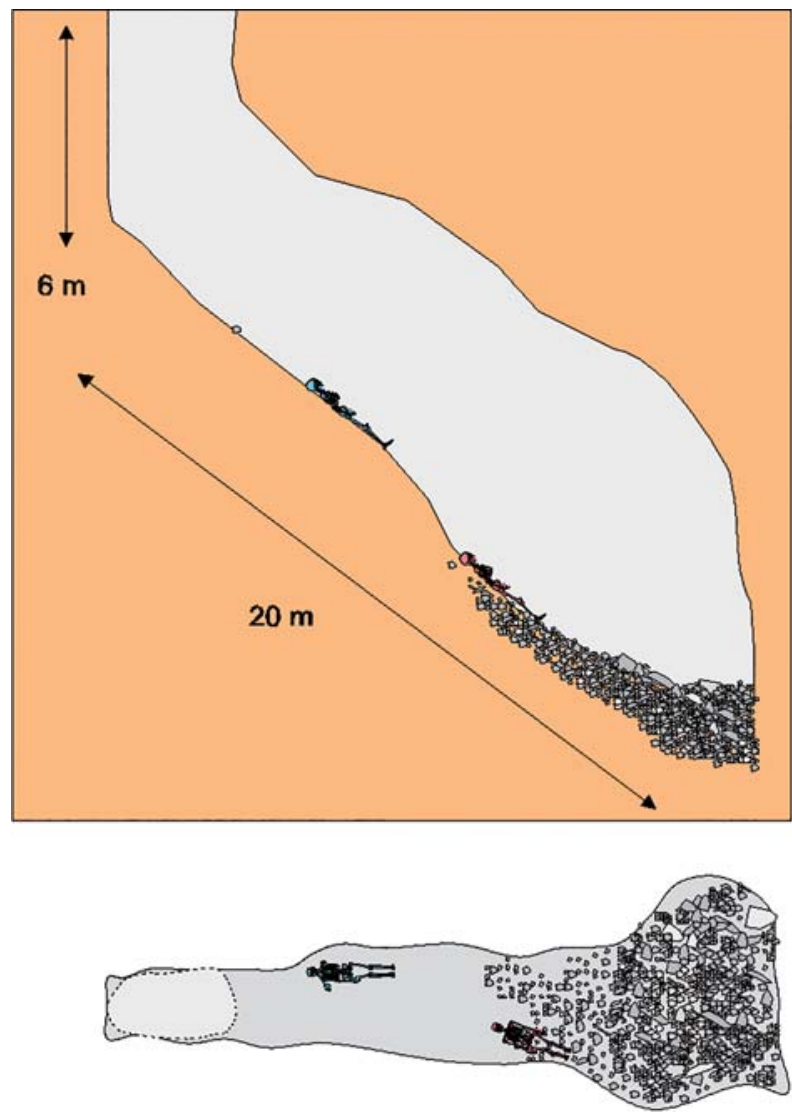

Fig. 2. Representación de la sima de Bedoña y localización de los restos. / Section and plan of Sima de Bedoña with the position of the remains.

\footnotetext{
${ }^{7}$ Existe informe específico de fecha 10 de enero de 2003, de 23 páginas (Archivo Sociedad de Ciencias Aranzadi). Miguel Bolinaga, hijo del caserío Garaikoa de Bedoña, de 81 años, recuerda el color azul de los buzos que vestían los dos milicianos que recalaron en su casa aquel fatídico 25 de septiembre de 1936. No recuerda el armamento que portaban, pero cree que se trataba de «combatientes republicanos que habían sido enviados a reforzar las defensas ante el avance de las tropas procedentes de Larrino". Fueron abatidos por disparos de ametralladoras situadas en el campanario de la iglesia y en el caserío Sologaisto.
} 


\section{SIMA VOLCÁNICA DE JINAMAR (Telde, Gran Canaria)}

Se trata de una chimenea de volcán de amplias dimensiones que presenta una profundidad de unos $75 \mathrm{~m}$. Tras una serie de saltos verticales, la cavidad continúa en fuerte rampa como consecuencia del inmenso cono de derrubios con abundantes piedras sueltas (Fig. 3). Esta protegida por ley desde 1999 y es Sitio de Interés Histórico desde 1996.

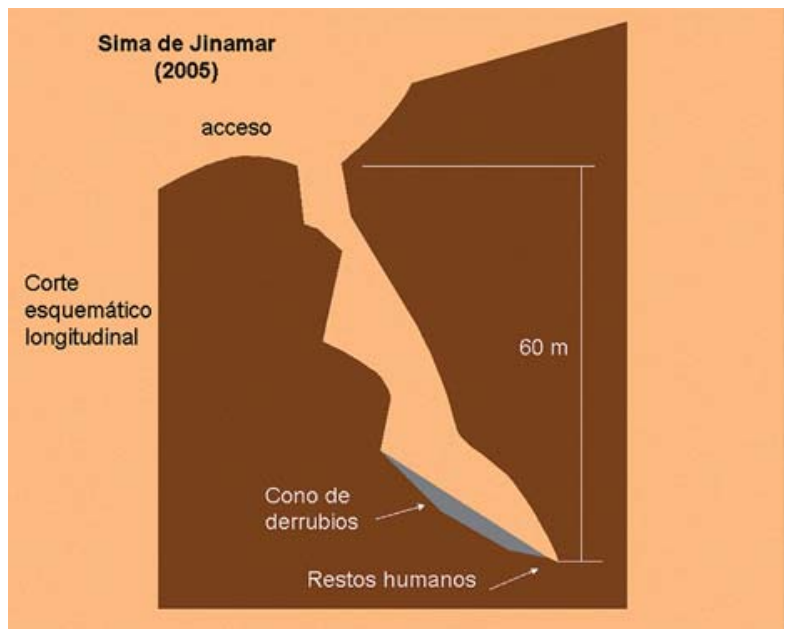

Fig. 3. Representación de la sima y localización de los restos. / Section of Sima de Jinamar and position of the remains.

En fecha 8 de octubre de 2005, realizamos una inspección a la cavidad siguiendo las indicaciones del Sr. Jesús Cantero, que había descendido en varias ocasiones a partir de 1967 con el Comité Canario de Espeleología comprobando la existencia de restos humanos en su interior que se atribuyen a la Guerra Civil española8. Al parecer, con anterioridad habían descendido al mismo lugar miembros del Grupo de Espeleología El Bohio que vieron un total de 13 esqueletos en conexión anatómica.

Siguiendo la misma fuente se han visto en la superficie del cono de derrubios hasta un total de 20 esqueletos con objetos personales como zapatos, botas, etc. En efecto, a lo largo de los últimos años, el lugar ha sido visitado por varias personas y se han recuperado algunos restos humanos que se encuentran depositados en el Museo Canario de Las Palmas de Gran Canaria9. Uno de los fragmentos craneales presenta una herida por arma de fuego en la región frontal, si bien los restos no han sido estudiados.

Durante nuestra visita en 2005 comprobamos que en el fondo de esta cavidad natural se conservan algunos restos humanos que se han debido recuperar de entre el enorme derrubio natural en el que también existen desperdicios de toda clase que han sido arrojados desde la boca de acceso.

En concreto los huesos humanos que identificamos dispersos en la galería son los siguientes: Coxal derecho con fusión al sacro (sacroileitis). Dos húmeros izquierdos. Dos tibias derechas. Radio derecho. Tres fragmentos craneales (dos del área occipital) (pertenecen a dos individuos). Escápula izquierda. Vértebra dorsal con osteofitos (artrosis). Vértebra lumbar (L4 o L5) (adulto joven). Fragmento de maxilar superior ${ }^{10}$.

Con posterioridad, estos huesos han sido recogidos por miembros de la Guardia Civil en el curso de la investigación sobre los niños desaparecidos. En 2012, el Instituto de Medicina Legal de Las Palmas (Dr. Pestano) realiza análisis de ADN para ver si los restos pertenecen a vecinos de Agaete.

\section{SIMA DE KRISTOLEZE (Lizarraga-Sierra de Andia, Navarra)}

Se encuentra registrada en el Catálogo espeleológico de Navarra con el n 144. Situada cerca del túnel de Lizarraga en dirección a la fuente de Estaniturri. Boca abierta en diaclasa dirección N-S, de $2 \times 0,75$ m. Pozo estrecho en sus primeros $15-18 \mathrm{~m}$, con las paredes pulidas. Luego se ensancha al llegar a la sala, siendo una vertical total de 40 $\mathrm{m}$, que acaba en pendiente por caos de bloques. Los restos se hallaron en la rampa mezclados con la basura arrojada del exterior.

La pendiente acaba en marmita, sigue la galería que acaba en zona con mucho goteo. Antes de llegar al final, a la izquierda hay una colada y parte otra galería en dirección contraria, muy parecida a la anterior y con mucho barro. En esta cavidad hay marcas de fluctuación de nivel, poco desarrollo. Coordenadas UTM: X 580.295, Y 4.743.262, Z 941.

En fecha 19 de noviembre de 2010, especialistas del Grupo de Rescate e Intervención en Montaña de la Guardia Civil (GREIM) y del Cuerpo Nacional de Policía proceden a la recuperación de restos óseos de unas diez personas en esta sima que habían sido hallados por un grupo de espeleólogos de la Asociación Gorosti de Pamplona. Sin que exista precisión sobre su cronología, se interpreta que puedan pertenecer a la Guerra Civil, aunque algunas fuentes señalan que pueden ser anteriores. Los restos fueron inspeccionados in situ y posteriormente trasladados a la Unidad Central de Identificación, Sección de Antropología Forense, de la Comisaría General de Policía Científica en Madrid.

\footnotetext{
${ }^{8}$ En este caso descendemos cuatro personas con el fin de realizar una inspección y tomar imágenes para TVE de cara a un documental sobre la represión durante la Guerra Civil bajo al dirección de Alfonso Domingo: "La memoria recobrada. Huesos", con Pedro Guerra. Guión, Cirilo Leal y Enrique Brasó. Realización, Enrique Brasó. Imagen, Juan Barco. Música, Pedro Guerra. En opinión del historiador Dr. Sergio Millares, en esta sima fueron arrojadas cerca de un centenar de personas (28 de Agaete, de Las Palmas de Gran Canaria y otros procedentes de Telde).

${ }^{9}$ En un reportaje publicado en "EdiciónCanarias7.es" por Angeles Arencibia el 4-01-2009, se muestran algunas fotografías de los restos conservados en el Museo Canario que pertenecen a cuatro o cinco personas. Con anterioridad, ya en 1977, Interviú hizo un reportaje de esta cavidad. ${ }^{10}$ Existe informe específico de fecha 10 de octubre de 2005, de 2 páginas (Archivo Sociedad de Ciencias Aranzadi).
} 


\section{SIMA DEL RASO DE URBASA (Sierra de Urbasa, Navarra)}

Se sitúa a la derecha de la carretera NA-7182 que atraviesa el raso de Urbasa que va desde el Palacio del Marqués de Andía (construido a finales del siglo XVII por Fernando Martínez de Baquedano) hacia Zudaire y EsteIla. Coordenadas: Latitud 42 48' 36" Norte / Longitud $2^{\circ}$ 9' 24" Oeste. UTM: X 568.940. Y 4.740.150.

Se trata de una cavidad natural con entrada vertical de $10 \mathrm{~m}$ que se abre en una sala espaciosa. Fue explorada por primera vez el año 1950 por miembros del Grupo de Espeleología de Estella entre los que se encontraba Eu- tenecientes a varios vecinos de Eulate en otoño de 1936. Sobre el año 1956, familiares de Balbino García cierran la entrada a la sima con un enlosado y se coloca una lápida (Fig. 4) con los nombres de algunas de las víctimas: Balbino García, Gregorio García y Balbino Bados.

En fecha 24 de marzo de 2013 contando con el correspondiente permiso del Departamento de Presidencia del Gobierno de Navarra procedemos a la apertura de la sima comprobando la existencia de restos de diez personas en buen estado de conservación que son exhumados para su análisis (Fig. 5) logrando la identificación de cuatro ellas por ADN en 2014 lo que ha permitido conocer la identidad de todo el grupo.

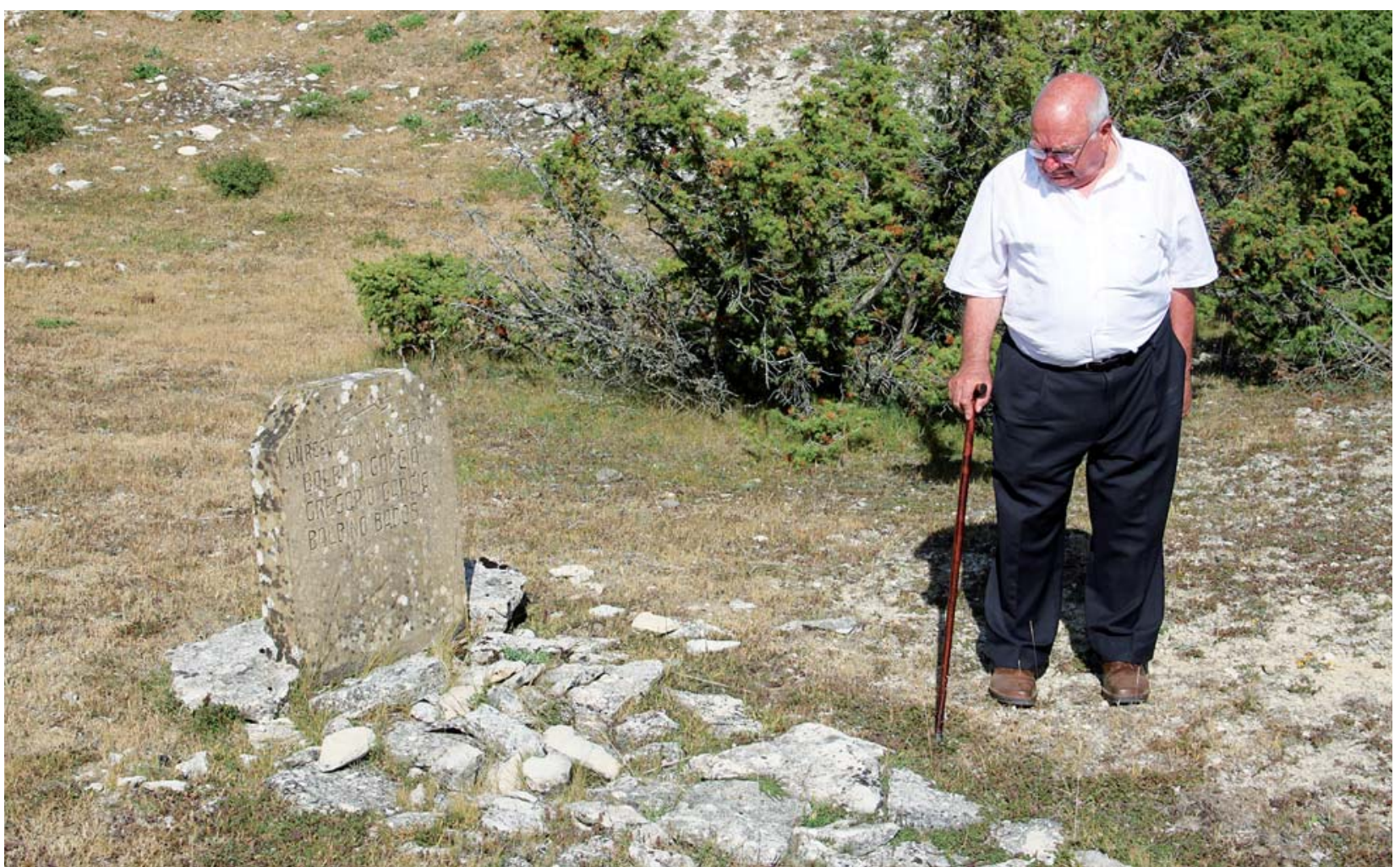

Fig. 4. Lugar señalizado en donde se encuentra la sima del Raso de Urbasa. / The marked position of Sima del Raso de Urbasa.

genio Roa ${ }^{11}$. Según este informante, en el suelo de la sala vieron entre dos y tres esqueletos humanos que presentaban ropas muy degradadas Ilamando la atención que uno de ellos se había desplazado varios metros interpretando que debió ser porque estaba vivo cuando lo arrojaron. Posteriormente otros miembros del mismo grupo de espeleología inspeccionaron la cavidad comprobando que hay una grieta por donde continúa la misma y en ella hay otro esqueleto más.

Los pastores de la zona conocieron los hechos, esto es el fusilamiento y posterior ocultación de los cuerpos per-

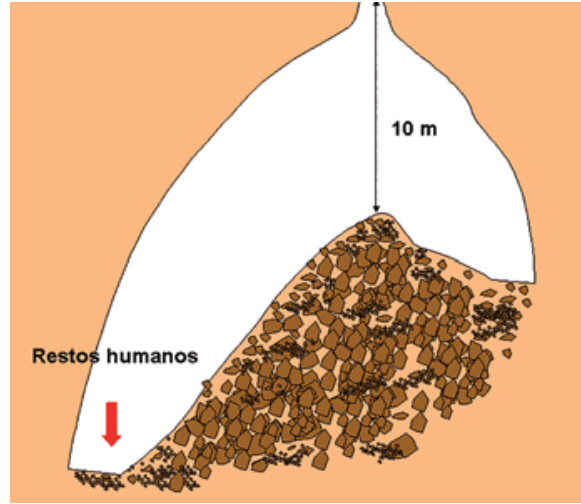

Fig. 5. Plano de la sima del Raso de Urbasa. / Plan of Sima del Raso de Urbasa.

\footnotetext{
${ }^{11}$ Tomamos testimonio que se graba en video (Archivo Sociedad de Ciencias Aranzadi).
} 


\section{SIMA DE ARDAITZ}

En 1985 el Grupo de Espeleología Satorrak de Pamplona recupera dos cráneos de esta sima que se encontraban al pie de una vertical de entrada de 37 m (Fig. 6) y se interpreta que corresponden a víctimas de la Guerra Civil (1936-1939).

La sima está situada en la sierra de Labia remontando el valle del Erro a Ardaitz. Se encuentra referenciada en el Catálogo Espeleológico de Navarra con el n 481. Coordenadas UTM X 627291 / Y 4.750.086 / 900

Se trata de dos cráneos humanos con fracturas por trauma directo si bien no se aprecian lesiones por impacto de proyectil de arma de fuego:

\section{Cráneo 1 Ardaitz}

Completo aunque fragmentado en la órbita izquierda con línea de fractura que recorre transversalmente el cráneo por el lado izquierdo del parietal, temporal y occipital. Conserva 8 dientes.

Pertenece a un individuo masculino de edad adulta joven de unos 20 años. Como variabilidad presenta dos facetas en los cóndilos occipitales y fusión con sinostosis prematura de la sutura parieto-temporal del lado izquierdo.

El cráneo se encuentra tratado con consolidante.

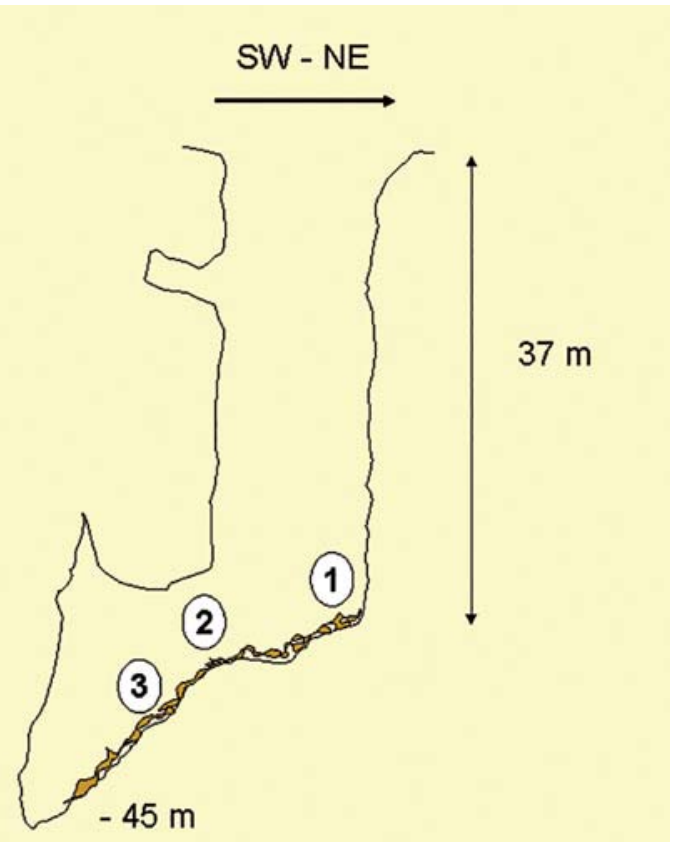

Fig. 6. Corte longitudinal de la sima (modificado de G.E. Satorrak). En se señala el esqueleto completo. En 2 la tibia y en 3 el fragmento de fémur perteneciente al segundo individuo. / Section of the shaft (modified from a G. E. Satorrak survey). 1 marks the position of the whole skeleton; 2, tibia and 3 , femur fragment, belonging to the second individual.

\section{Cráneo 2 Ardaitz}

Incompleto, falta todo el esplacnocráneo por fractura anterior en región frontal. En el lado derecho del occipital presenta una perforación irregular de $7 \mathrm{~mm}$ de diámetro mayor ocasionada por golpe directo en la tabla externa con bisel por arrancamiento en la interna.

Pertenece a un individuo masculino de edad adulta joven cercana a los 20 años.

En visita efectuada el 23-12-2012 comprobamos que al pie de la vertical se conserva un esqueleto casi completo en justa relación con el cráneo 2 descrito. Asimismo, en la pronunciada rampa al fondo de la sima localizados un fémur y una tibia que deben corresponder al otro individuo representado por el cráneo 1.

\section{SIMAS DE DOLENCIAS (Sotoscueva, Burgos)}

Con motivo de las exhumaciones llevadas a cabo en la comarca de Las Merindades al norte de Burgos en las fosas de Loma de Montija, Alto de La Mazorra y Espinosa de Los Monteros se han suscitado algunas dudas respecto a la posible existencia de más restos humanos en simas del complejo kárstico de Ojo Guareña.

De conformidad a la información publicada en la página web de Las Merindades con base en testimonios orales, se tiene constancia de que pueden ser varios los vecinos arrojados a las simas de Dolencias ${ }^{12}$. OBREGÓN (2014) publica un listado con los nombres de algunas de estas víctimas señalando que esta cavidad fue utilizada con el mismo fin durante las guerras carlistas del siglo XIX.

Posteriormente, a iniciativa del cura de Cueva, a principios de los años 50 una empresa de origen alemán situada en Luchana vació los huesos de la sima para fabricar fosfatos en una empresa conocida como "La huesera". Se trasladaron cientos de cajas con huesos en el tren de La Robla, pero debido a las quejas por los olores se terminó haciendo en camiones. Años más tarde cuando llegaron los espeleólogos a esta sima, no encontraron casi nada.

\section{SIMA DE GAZTELU (Gaztelu, Navarra)}

Se trata de una profunda sima localizada al sur de Gaztelu (Navarra) en una zona boscosa y de montaña (Fig. 7). Referenciada en el Catálogo Espeleológico de Navarra con el n 468. Se sitúa al SE de Gaztelu a 10 m de la pista forestal que hay en el lugar. Coordenadas Geográficas 43 7' 0" N, 10 38'15" W. UTM: X 610.837, Y 4.774.792.

Presenta una vertical de $40 \mathrm{~m}$ con fondo de derrubios. Según diversos testimonios, que se publican en el libro "Navarra de la esperanza al terror" como consecuencia de la Guerra Civil fueron movilizados el padre y un hijo de

${ }^{12}$ El listado de las posibles víctimas puede encontrarse en: http://lasmerindadesenlamemoria.wordpress.com/2011/06/06/las-simas-de-dolenciassotoscueva/ 
la familia Sagardía que eran vecinos de este municipio, quedando su mujer y otros seis hijos menores en situación muy precaria. Finalmente fueron denunciados por otros vecinos ante la Guardia Civil por realizar pequeños hurtos. Por tal motivo la familia tuvo que trasladarse al monte a una chabola cercana a la sima donde desaparecieron.

La familia estaba emparentada con el General Antonio Sagardía Ramos y ello supuso una investigación oficial de los hechos con apertura de diligencias judiciales en 1937 (Juzgado de Primera instancia e Instrucción n 1 de Pamplona, Diligencias 167/1937 sobreseídas en 1946) y la detención de varios vecinos que fueron conducidos a la cárcel de Pamplona.

En cualquier caso los hechos no fueron esclarecidos y se interpretó que tras los asesinatos de toda la familia ${ }^{13}$, los cuerpos fueron arrojados a la sima. Los bomberos de Pamplona trataron de bajar a esta sima sin conseguirlo.

A solicitud de la S.C. Aranzadi, en diciembre de 2014 el grupo de espeleología Satorrak desciende al fondo de la sima y descubre un cadáver reciente cuyo hallazgo es notificado al Juzgado de Instrucción n 4 de Pamplona. Por ello el día 26 de diciembre de 2014, intervenimos en la recuperación de estos restos acompañando a la Policía Foral y a responsables del Instituto de Medicina Legal de Navarra. Además, en el fondo de la sima de $50 \mathrm{~m}$ de profundidad, se acumulan abundantes desperdicios y basuras que habría que retirar para comprobar si hay restos óseos de las víctimas de la Guerra Civil.

\section{SIMA TORCA PALOMERA} (Mozuelos de Sedano, Burgos)

Castro (2007), en su completo trabajo sobre la represión en Burgos señala que varias personas fueron arrojadas por precipicios ${ }^{14}$, como Torca Palomera en Mozuelos de Sedano, o los cañones del río Ebro.

La sima o torca Palomera se encuentra situada en el municipio de Mozuelos de Sedano. Se llega por la carretera a Santander N-623 una vez ascendido el páramo de Masa que conduce a Sedano. En realidad no hay que llegar hasta el pueblo, pues hay que desviarse por un camino bien marcado que parte a la izquierda de la carretera y a unos dos kilómetros del cruce. Por este camino se llega directamente a la sima. La entrada al pozo es grande: 15 por $5 \mathrm{~m}$ y el fondo está a $60 \mathrm{~m}$ de profundidad. La cueva tiene forma de un embudo invertido y las paredes son lisas. El suelo tiene el consabido cono de derrubios, pero repleto de basuras hasta resultar nauseabundo. Medicamentos, latas, abonos, chatarra, animales en descomposición, etc.

Según algunas fuentes (como la de Jesús Gutiérrez Flores en "Guerra Civil en Cantabria y pueblos de Castilla"), fueron lanzados unos 40 militantes de izquierdas a la sima. Pero es probable que fuesen muchos más.

\section{COVA ARCOIA (Sierra del Caurel, Lugo)}

En 1992 el equipo multidisciplinar del Geólogo del Instituto Xeolóxico de Laxe (A Coruña), Juan Ramón Vidal Ro-

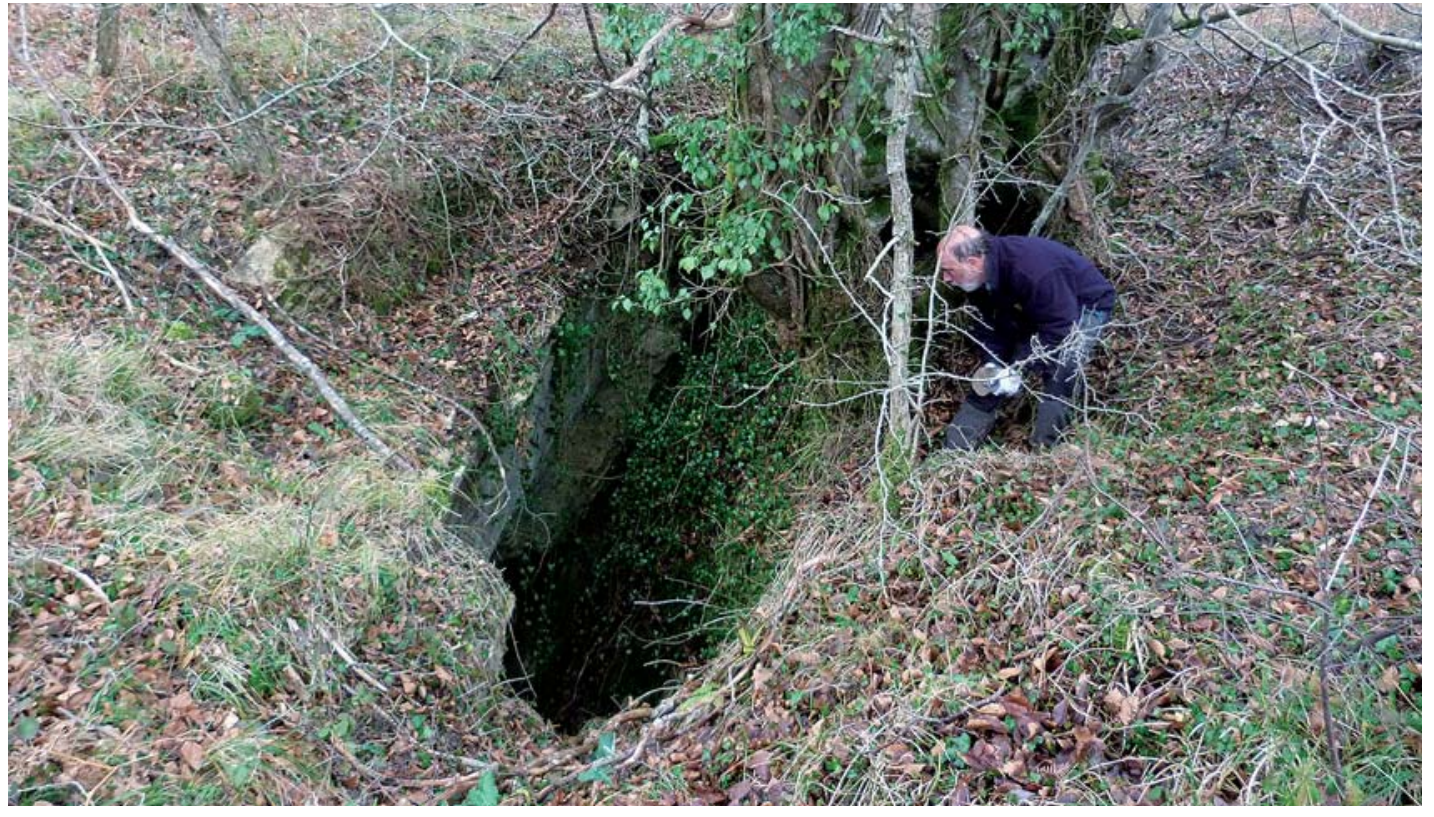

Fig. 7. Boca de la sima de Gaztelu (1301-2013). / Entrance of the shaft of Gaztelu (13/1/2013).

\footnotetext{
${ }^{13} \mathrm{~A}$ su regreso de la guerra, el padre falleció y su hijo mayor marchó a Francia.

${ }^{14}$ Precipicios, barrancos, acantilados y ríos también fueron utilizados en muchos lugares. Entre otros el "Balcón de Pilatos" (Navarra) y El Barranco de El Carrizal de Orgiva (Granada). En este, según el historiador Juan González Blasco, era un auténtico matadero y cementerio de seres humanos, procedentes de los pueblos de la Alpujarra. En la parte de arriba del barranco, encima del actual puente, hay 149 personas fusiladas y entre ellos, una mujer conocida en Órgiva por N., que era madre de 11 hijos. Con respecto a los acantilados, fueron numerosos. Por citar algunos: Cabo Mayor (Santander), Garrat (Barcelona), Paseo Nuevo (San Sebastián),
} 
maní estudia los únicos montes kársticos de Galicia en la Sierra del Caurel (Lugo). En una de sus cuevas llamada Cova Arcoia (coordenadas geográficas $42^{\circ} 36^{\prime} 46,57^{\prime \prime} \mathrm{N}$ y $7^{\circ}$ 5' 3,20" W. UTM: X 657.131, Y 4.719.612), encuentran dos cráneos humanos, algún diente suelto y varios huesos largos que nos remiten para su estudio antropológico con la esperanza de hallar los primeros restos humanos paleolíticos. Se estima un número mínimo de tres individuos considerando un cráneo femenino, otro masculino y restos de un individuo subadulto. Se practica estudio de datación por Carbono 14 mediante el sistema de aceleración de particulas (APS) que se practica en el Laboratorio de Svedberg (Suecia). Se envían tres muestras: una de cada cráneo y un canino. El cráneo masculino arroja una data de 135+/-50 años BP (1807-1912), el cráneo femenino arroja una data de 150+/-50 años BP (1792-1892) y el canino llega a 210+/-50 años BP (1732-1832). Los cráneos muestran signos de violencia. Los huesos largos líneas de Harris. A pesar de la aparente precisión de la datación consideramos que el margen de error de esta técnica es superior a los +/-50 años que indica el informe de resultados, ${ }^{15}$ por lo que consideramos en su momento que los restos óseos podrían pertenecer a la Guerra Civil y por supuesto compatible también con periodos anteriores próximos (siglo XIX) (SERRULLA y ETXEBERRIA, 1995).

En 2009 un grupo de espeleólogos localizan en Cova Arcoia en el mismo lugar más restos humanos, objetos asociados y una vaina disparada de un fusil. En esta ocasión interviene el Juzgado competente, el Grupo de Montaña de la Guardia Civil de Pobra de Trives y la Unidad de Antropología Forense del Instituto de Medicina Legal de Galicia junto con un equipo de Médicos Forenses de la Subdirección de Lugo. Cova Arcoia es una cueva muy conocida por los espeleólogos locales y es de compleja entrada. Los restos óseos se encontraban en una zona de derrumbe en forma de embudo rellenada por fragmentos de piedra a la que se accede de dos maneras: a) Desde una entrada que requiere reptar y que tiene una caída libre de unos 5 metros hasta la cámara de los huesos, y b) A través de un descenso serpenteado entre grandes rocas que lleva hasta la zona más alta de una gran rampa de piedras que acaba donde estaban todos los restos óseos La temperatura en el interior de la cueva es de 7-9 $9^{\circ} \mathrm{C}$ (mes de julio, altitud estimada: 1800 metros) con humedad relativa en torno al 90\%. Los huesos se hallan dispuestos sin conexión anatómica alguna, excepto la pierna izquierda de un individuo subadulto que está unida a una bota de cuero. Entremezclados con los huesos humanos encontramos muchos huesos de animales domésticos. La totalidad de los huesos se hallan en el nivel superficial y en los primeros $30 \mathrm{~cm}$ de piedras. El análisis químico de la tierra (pequeños fragmentos de piedras) revela que se trata de un medio de $\mathrm{pH}$ alcalino
$(7,8)$ con altos niveles de Calcio. En las proximidades de los huesos se halla una vaina percutida que se remite al Laboratorio de Balística de la Guardia Civil y que es informada como un culote de calibre .58 de la marca Remington Berdan (41×15 mm) disparado y que se empezó a fabricar en España en 1867 para cambiar los fusiles del ejército español que hasta entonces eran de avancarga. Los datos históricos de esta munición sitúan su origen principal en la Fábrica de armas de Asturias y se hizo para mejorar las armas del ejército. Según el laboratorio de Balística de la Guardia Civil la munición Remington Berdan se usó desde la tercera guerra Carlista hasta la Guerra Civil esencialmente. No obstante de forma muy ocasional estos cartuchos aparecen incluso en los últimos años.

Contemplados los huesos hallados en 1992 así como los localizados en 2009, el inventario completa casi totalmente dos esqueletos. Uno de un varón adulto joven (2530 años) con signos de traumatismo craneal severo (fractura-hundimiento témporo-parietal sin conservar fragmentos y arcos de fracturas secundarias no compatible con disparo de arma de fuego), fractura de diáfisis de fémur con un fragmento y signos de supervivencia mínima (días). El otro esqueleto pertenece a un individuo subadulto de edad estimada entre 10 y 14 años que genéticamente se corresponde con un varón. Este individuo presenta un traumatismo craneal severo con un orificio occipital derecho compatible con orificio de salida de disparo de arma de fuego. La ausencia de la zona témporoparietal izquierda no permite acreditar la existencia de orificio de entrada, pero existe compatibilidad en relación con hipotética trayectoria. Este individuo presentaba también fractura vertebral dorsal alta (D2-D3) del arco y el cuerpo, hiperostosis porótica costal, fractura costal incompleta y líneas de Harris. La bota hallada en conexión con la pierna del individuo subadulto está manufacturada completamente en cuero (incluidos cordones y suela), sin marcas o logotipos.

Nos pareció extraño que un niño con un disparo de arma de fuego en la cabeza se hallara en el fondo de una cueva. Por ello remitimos una muestra de hueso para estudio genético forense. El perfil genético demostró que se trataba de un varón y se introdujo en la nueva base de datos de ADN de desaparecidos del Instituto Nacional de Toxicología y Ciencias Forenses ADNID, resultando negativa hasta la fecha la coincidencia del perfil genético con ninguno de los introducidos.

En síntesis, los huesos pertenecen a dos individuos varones no identificados. Un adulto joven de 25-30 años con signos de muerte violenta por traumatismo craneal severo y politraumatismo con supervivencia mínima y otro subadulto de edad estimada entre 10 y 14 años con sig-

\footnotetext{
${ }^{15}$ Una de las principales fuentes de error del sistema de datación por Carbono 14 (incluidos los métodos químicos, por acelerador de partículas y otros) es que la muestra esté contaminada por C14 procedente del agua en contacto con otros seres vivos (plantas esencialmente). Otra fuente de error es que en realidad el nivel de C14 del que se parte para estimar la data es una estimación tanto en lo relativo al lugar como al nivel cuantitativo del que se parte. Por otro lado teniendo en cuenta que los resultados de las tres muestras no son coincidentes a pesar de aparecer en el mismo contexto y mismo nivel arqueológico, pensamos que debe existir un margen de error mayor del aportado por el experto analista.
} 
nos de disparo de arma de fuego en la cabeza, politraumatismo y evidencias de estrés nutricional.

Los únicos datos históricos con los que contamos hacen referencia a la escritora de Sarria (Lugo) Mercedes Vazquez Saavedra en su Guía O Courel publicada en 2003. En la sección dedicada al pueblo de Visuña (parroquia en la que se encuentra Cova Arcoia) recoge la referencia oral de vecinos que dicen haber oído comentarios respecto a la muerte de carlistas que fueron trasportados sus cadáveres a Cova Arcoia $^{16}$. Existen también referencias de que estos montes sirvieron de refugio a maquis y republicanos en la época de la Guerra Civil y años posteriores, dado que el es un lugar de paso de los montes de León a Galicia y que se trata de una ubicación recóndita. Es importante saber que es necesario conocer su existencia y su localización para poder llegar a esta cueva.

Tenidos en consideración todos los datos obtenidos nos parece razonable afirmar que aunque los restos pudieran corresponderse a la época de la tercera guerra carlista (1872-1876), es quizás más probable que pertenezcan a la Guerra Civil. La tercera guerra carlista no tuvo en Galicia frente de guerra, aunque sí hay constancia de escaramuzas en diferentes zonas del territorio. Quizás uno de los elementos clave en este caso puede ser la vaina hallada. Se trata de un elemento que nos da una data mínima (1867) aunque nos parece poco probable que apenas 5 años después de empezar a fabricarse se usara ya en este escondido lugar. Por otro lado los fusiles que emplearon esta munición se usaron sobre todo en la Guerra Civil. Por este motivo y por las lesiones traumáticas halladas pensamos que los restos pueden pertenecer a la época de la Guerra Civil española.

\section{CUEVA DE HUMARRAÑA}

\section{(Loma de Montija, Burgos)}

Situada en la localidad de Loma de Montija (Burgos). Coordenadas $43^{\circ} 02^{\prime}$ 57" latitud Norte, $3^{\circ} 28^{\prime} 34^{\prime \prime}$ longitud Oeste. La cavidad tiene un resalte vertical de $6 \mathrm{~m}$.
Cavidad conocida en la Merindad Montija en donde se interpreta que fueron arrojados varios cadáveres en septiembre de 1936. En su exterior hay un monolito relativo a estos hechos. Entre mayo y junio de 2009 miembros del Foro por la Memoria realizan una inspección descubriendo restos de dos individuos en la misma superficie de la cueva, atendiendo los intereses de Dña. Rufina Balbás (hija de una de las víctimas) defendida por la letrada Dña. Virginia Díaz.

Esta circunstancia fue notificada al Juzgado de Instrucción $n^{\circ} 2$ de Villarcayo que abrió Diligencias Previas $n^{\circ}$ 261/09. Por tal motivo actuó el Equipo de Rescate e Intervención en Montaña (GREIM) de la Guardia Civil con base en Ezcaray (La Rioja), que extrajo los restos (2-02-2010) y fueron en primera instancia analizados por médicos forenses del Instituto de Medicina Legal de Burgos. Posteriormente se realizó un análisis antropológico por parte de facultativos forenses del Instituto Nacional de Toxicología y Ciencias Forenses ${ }^{17}$ de Madrid que lograron la identificación de uno de los esqueletos en la persona de Rufino Balbás Alonso con una probabilidad de paternidad de $99,9987 \%{ }^{18}$.

\section{POZOS DE CAUDE (Teruel)}

Situado a $10 \mathrm{~km}$ de Teruel en la carretera N-234 Sagunto a Burgos. Se trata de un pozo artesiano de $2 \mathrm{~m}$ (Fig. 8) de diámetro y $84 \mathrm{~m}$ de profundidad en donde se interpreta que fueron ocultados más de mil cadáveres pertenecientes a víctimas republicanas fusiladas entre agosto de 1936 y diciembre de 1937. Si bien no se han llevado a cabo labores de inspección del pozo que se encuentra colmatado con tierra, son muchos los que aseguran que en el lugar hay centenares de personas ${ }^{19}$.

Las coordenadas geográficas son $40^{\circ} 22^{\prime} 26^{\prime \prime} \mathrm{N}, 1^{\circ} 9^{\prime}$
$45^{\prime \prime}$ W. UTM X 656.985, Y 4.470.904.
El año $1979-1980$ se colocó un monumento que re-
cuerda a estas víctimas y la Asociación Pozos de Caudé
convoca todos los años un acto de homenaje el día 1 de
Mayo 20 . En 2007 se ha creado un parque con motivo de
la urbanización del espacio para el polígono industrial

\footnotetext{
${ }^{16}$ «Aquí o que houbo foron carlistas, o que teño escoitado, o que dicía o meu avó, é que a algún carlista o mataron aquí mesmo, matárono no outeiro, escondérono no muín e transportárono á cova de Arcoia, en Céramo» (VAZQUEZ, 2003).

${ }^{17}$ Existe un amplio informe de fecha 21-09-2010 con inventario y descripción de los restos de 55 páginas, así como otro específico de fecha 18-072011 sobre el análisis de ADN y sus resultados de 5 páginas. Por tal motivo el esqueleto identificado ha quedado a disposición de los familiares. ${ }^{18 R u f i n o ~ B a l b a ́ s ~ A l o n s o ~ e r a ~ f u n c i o n a r i o ~ d e ~ p r o f e s i o ́ n, ~ f u e ~ s e c r e t a r i o ~ d e l ~ A y u n t a m i e n t o ~ d e ~ F u e n t e o d r a ~ y ~ l o ~ e r a ~ d e l ~ A y u n t a m i e n t o ~ d e ~ V a l l e ~ d e ~ M a n z a-~}$ nedo en la fecha de su desaparición. Además, ejerció de secretario interino del Ayuntamiento del Condado de Treviño. Era natural de Villovela de Esgueva. Estaba casado con Cesárea Ayuso Hernando, con la que tuvo dos hijos, Cesáreo y Rufina. Fue miembro destacado de Izquierda Republicana en la provincia de Burgos desde su formación, y con anterioridad perteneció al Partido Republicano de Burgos. El asesinato se produciría el 19/08/1936. Se interpreta que el otro esqueleto pueda pertenecer a Ángel Ruiz Crespo, vecino de Incinillas, Villarcayo. Estaba casado, y tenía un hijo/a. El maestro fue paseado, siendo arrojado a la cueva de Humarraña, en el término municipal de Loma de Montija junto con el secretario de Manzanedo. Al maestro un día le sacaron de la escuela y le mataron de dos tiros. La esposa (Luisa) se quedó viviendo en Incinillas hasta que cayó enferma y se la llevó su familia, que vivía en Cernégula. (Archivo General de la Administración Ministerio de Educación Nacional Expedientes de depuración de maestros nacionales 32/13189 1936-1942).

${ }^{19}$ El listado de las víctimas en este lugar puede consultarse en http://www.nodo50.org/pozosdecaude/asesinados_pozos_caude.htm. No se debe equivocar este pozo con la fosa exhumada el año 2005 en los Llanos de Caudé (Teruel) por D. Alonso Císter, en donde se recuperaron 13 esqueletos y que fue promovida por la Asociación Pozos de Caudé (Alonso Cister, 2008). También se encuentra referenciado en el Mapa de Fosas de Aragón http://lamemoriaviva.files.wordpress.com/2008/11/mapa-fosas-aragon.pdf

20Puede consultarse abundante información de la Asociación en: http://www.nodo50.org/pozosdecaude/. Eduardo Martín Pozuelo publica en La Vanguadia (20/10/2002) un artículo específico destacando la importancia del trabajo realizado por los hermanos Volney y Jaurés Sánchez en la recuperación de este lugar de memoria.
} 


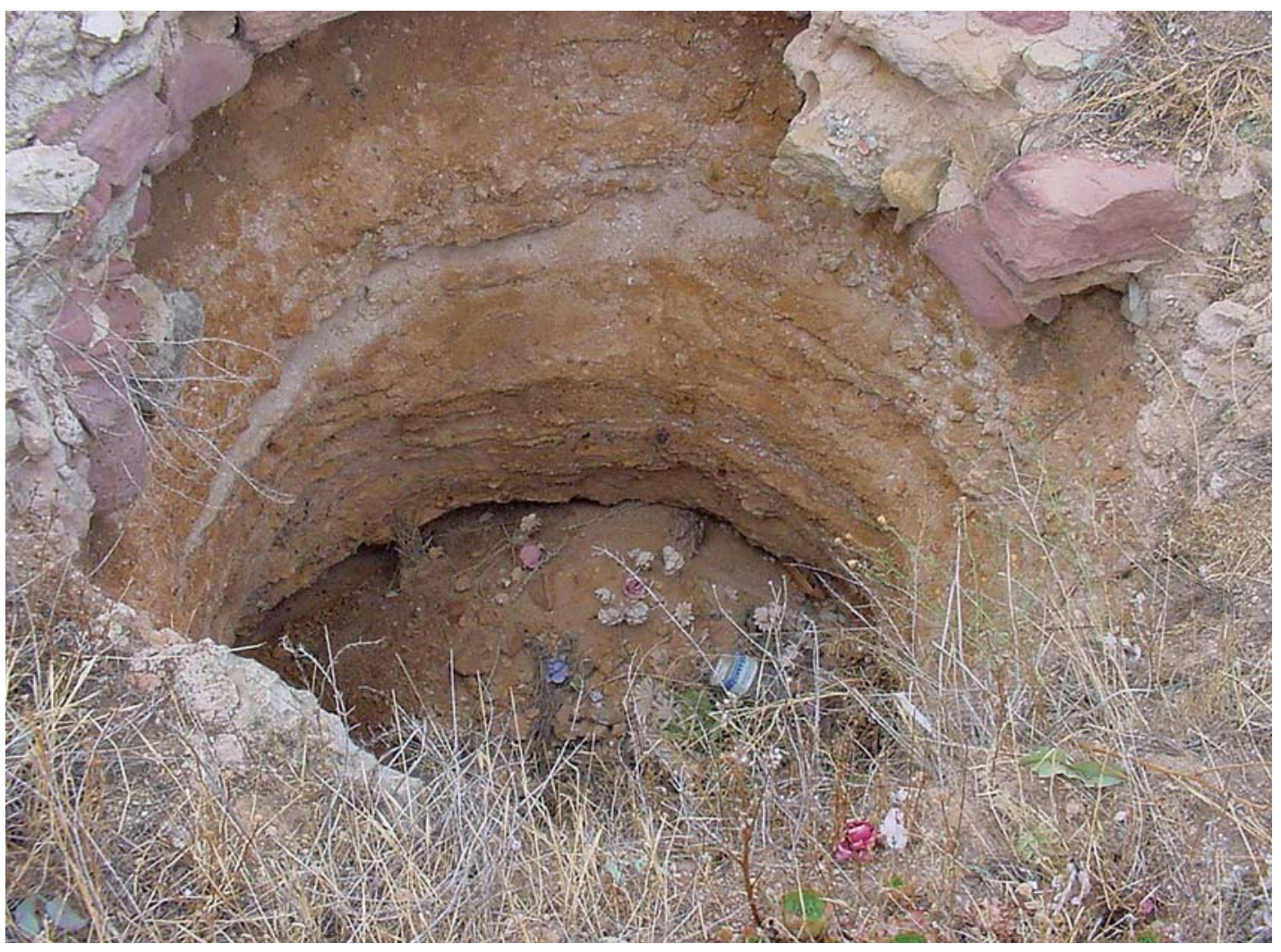

Fig. 8. Entrada al pozo de Caudé antes de las reformas del año 2007. / Entrance to Caudé Well, before the alterations in 2007.

Platea (Plataforma Logística e Industrial de Teruel) en su proximidad.

\section{POZO VENTAFARINAS}

\section{(Tamarite de Litera, Huesca)}

En donde fueron arrojados un número indeterminado de personas víctimas de la represión republicana. Posteriormente, el mismo lugar fue empleado para víctimas de la represión franquista ${ }^{21}$. El pozo se encuentra colmatado y mantiene un brocal como monumento con una cruz de piedra.

Coordenadas UTM X 280.390, Y 4.626.215, Z 239, en la localidad de Tamarite de Litera lindante con la comunidad catalana.

\section{POZO DEL LLANO DE LAS BRUJAS (Arucas, Gran Canaria)}

Existen varios pozos artesianos en la isla de Gran Canaria que fueron aprovechados para esconder los cadáveres de los crímenes cometidos durante los primeros meses de la Guerra Civil con alguna evidencia de uso en marzo de 1937. Tales son los pozos del Llano de Las Brujas (Montaña Blanca), Barranco de Tenoya, Puente del barranco de Arucas, Vuelta del Ayuntamiento (del francés) y Martorell.

De ellos ha sido investigado el Pozo del Llano de Las Brujas $^{22}$ en la localidad de Arucas, llamado también pozo de Don Paulino Granados, en donde se recuperaron los restos completos de 24 individuos el año 2009 por un equipo dirigido por José Guillén de la empresa Tibicena ${ }^{23}$ a solicitud del Ayuntamiento de Arucas.

Se accede por la carretera GC 301 de Arucas a Tenoya. Localización: UTM X 451.057 / Y 3.111.187 / Y 185.

Se trata de un pozo circular de $3 \mathrm{~m}$ de diámetro con una profundidad de $55 \mathrm{~m}$ en donde fueron arrojados los cadáveres en dos momentos distintos ya que se ha encontrado un hiato de separación entre un grupo de 14 esqueletos y otro superpuesto y posterior de 10 esqueletos.

El estudio antropológico ha permitido establecer la muerte como consecuencia directa de las lesiones por arma de fuego que presentan los restos con predominio

\footnotetext{
${ }^{21}$ Referenciado en el Mapa de Fosas de Aragón http://lamemoriaviva.files.wordpress.com/2008/11/mapa-fosas-aragon.pdf ${ }^{22}$ Existe un informe muy completo de 222 páginas, firmado por Félix Mendoza, Marco Moreno e Ibán Suarez con un análisis antropológico y abundante documentación fotográfica realizado por Martha Alamón.
}

${ }^{23}$ Gabinete de Estudios Patrimoniales S.L. 
en el territorio cefálico. De este conjunto han sido identificados 9 individuos por el Dr. José Pestano del Laboratorio de Genética de la Universidad de Las Palmas de Gran Canaria.

Junto con los restos se hallaron abundantes objetos personales y cal, así como 36 proyectiles o fragmentos y 30 vainas. En el exterior, junto a la boca del pozo, se recuperaron 3 vainas y 2 proyectiles.

\section{POZO-MINA DE VALDIHUELO (Alburquerque-San Vicente, Badajoz)}

Se trata de una cata minera de prospección con una profundidad de 11,90 $\mathrm{m}$ de aspecto redondeado de 3,20 $\times 2,27$ m de diámetro situada a la izquierda de la carretera EX-110. Coordenadas geográficas $7^{\circ} 5^{\prime} 30^{\prime \prime} / 39^{\circ}$ 19' 45" en el término municipal de Valencia de Alcántara (Badajoz).

Se interpreta que en este pozo minero fueron arrojadas varias personas en los primeros meses de la Guerra Civil, si bien el lugar ha sido empleado para arrojar escombros y restos faunísticos hasta el punto de que se encontraba totalmente colmatado.

En fecha 2-12-2002 se realizan las primeras labores de extracción del escombro mediante el empleo de una pala excavadora en donde aparecen algunos huesos. Esto motiva la intervención formal para investigar su contenido bajo la dirección de los médicos Diego Peral y Mariano Casado con la colaboración de la arqueólogo Inmaculada LópezFlores a partir de 14-07-2003 hasta el 30-09-200324 en una primera fase, y posteriormente hasta su finalización el 1402-2004 en una segunda, en donde se recuperan restos parciales y fragmentarios de unas quince a diecisiete personas así como algunos objetos personales asociados. PERAL y col. (2010) publican el inventario de los restos con fotografías y señalan, citando fuentes orales, que en esta mina fueron arrojados entre 70 y 130 individuos.

\section{POZOS-MINAS DE CASTUERA (Badajoz)}

En el campo de concentración de Castuera ${ }^{25}$ (Badajoz) se interpreta que fueron aprovechados varios pozos mineros para arrojar cadáveres de personas que fueron fusiladas. Así en las minas de Vallehondo o de Somoza, mina Miraflores, mina Tetuán y mina de la Gamonita.

\section{POZO-MINA DE LAS CABEZUELAS (Camuñas, Toledo)}

Situada en la localidad de Camuñas (Toledo) a la derecha de la carretera A-IV antes de llegar a Puerto Lápice en una finca de olivos. Coordenadas: Latitud $39^{\circ} 22^{\prime} 3^{\prime \prime}$ Norte / Longitud 3 30' 14" Oeste. UTM: X 456.576 / Y 4.357.776.

A solicitud del Arzobispado de Toledo, entre el año 2008 y 2010 un equipo de la Sociedad de Ciencias Aran-

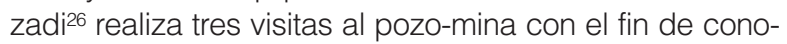
cer las características del lugar en donde fueron arrojados un número indeterminado de personas que fueron represaliadas por republicanos durante la Guerra Civil española (1936-1939)

En concreto, las visitas efectuadas por parte de este equipo de investigación constituido al efecto han sido: primera inspección del pozo, 25 de noviembre 2008; localización de los restos humanos, 24 a 31 de marzo 2009, análisis parcial de los restos humanos, 18 al 24 de enero de 2010.

En la tercera inspección realizada objetivo fue el siguiente:

a) Adecuación e instalación para descender al pozo con las necesarias medidas de seguridad.

b) Excavación arqueológica con exposición de los restos e interpretación in situ.

c) Documentación de todo el trabajo realizado siguiendo una metodología científica elaborando un informe técnico al respecto.

Por tal motivo llevamos a cabo las labores arqueológicas necesarias para exponer la mayor cantidad de restos humanos pertenecientes a los cadáveres arrojados al pozo de la mina. La interpretación fue realizada in situ sin extracción de los restos del interior de la mina. Los primeros dos días los dedicamos a la adecuación del pozo mediante la colocación de una grúa y una plataforma de seguridad en el fondo del pozo que permitiera el descenso sin peligro para quienes trabajaban al pie de la vertical a una profundidad de $30 \mathrm{~m}$ (Fig. 9). Al mismo tiempo fue necesario instalar una segunda

\footnotetext{
${ }^{24}$ Existe un informe técnico elaborado por Inmaculada López-Flores de 45 páginas en donde se recogen los resultados de esta intervención con el inventario de los restos hallados.

${ }^{25}$ Memorial Campo de Concentración de Castuera: http://www.memorialcastuera.blogspot.com.es/

${ }^{26} \mathrm{El}$ objetivo de esta investigación consistía en comprobar la veracidad de las fuentes documentales y orales teniendo en cuenta el proceso de beatificación en el que se encuentran los sacerdotes allí asesinados. Existe un informe ampliamente ilustrado con fotografías y dibujos de 201 páginas de fecha 02-08-2010. Coordinación: Jorge López Teulón (Sacerdote, Arzobispado de Toledo). Equipamiento e instalación del pozo: Tito Aguire (Sociedad de Ciencias Aranzadi). Sebas Lasa (Sociedad de Ciencias Aranzadi). Rafael Zubiria (Sociedad de Ciencias Aranzadi). Arqueología: Lourdes Herrasti (Licenciada en Geografía e Historia, Sociedad de Ciencias Aranzadi). Jimi Jiménez (Licenciado en Geografía e Historia, Sociedad de Ciencias Aranzadi). Almudena García Rubio (Licenciada en Geografía e Historia, Universidad Complutense de Madrid). Berta Martínez (Licenciada en Geografía e Historia, Universidad Complutense de Madrid). Fotografía y video: Rafael Zubiria (Sociedad de Ciencias Aranzadi). Antropología y patología: Francisco Etxeberria (Sociedad de Ciencias Aranzadi y Universidad del País Vasco). Luis Ríos (Antropólogo Físico, Universidad Autónoma de Madrid). Claudio Albisu (Médico dentista, Sociedad de Ciencias Aranzadi). Antropología Cultural: Francisco Ferrándiz (Antropólogo Social, Consejo Superior de Investigaciones Científicas, Madrid). María García Alonso (Dpto. Antropología Social, UNED). Colaboradores: Luis Avial (Condorgeorradar).
} 
plataforma casi en contacto del suelo ya que los restos humanos ocupaban toda la superficie y no se debía pisar directamente porque se hubiera producido su completa destrucción. Una vez resueltas estas cuestiones, comenzamos por dar prioridad a los restos situados en la zona de la rampa delimitando su distribución mediante la excavación de la mayor cantidad de tierra circundante. Con ello logramos también facilitar el paso entre el fondo del pozo y la galería lateral en donde se sitúa la rampa que es realidad un cono de derrubios repleto de esqueletos humanos.

Recordemos en este punto que ya en la inspección que llevamos a cabo en 2009 tras la retirada de varias toneladas de tierra, comprobamos que los restos que se encontraban en superficie, es decir los últimos arrojados al pozo, se hallaban carbonizados por el efecto del fuego intencionado realizado en ese lugar con material combustible (muy probablemente gasolina tal y como aseguran algunos testimonios).

La galería fue dibujada y se cuadriculó el área de trabajo para establecer las relaciones topográficas y de superposición de los restos (Fig. 10 y Fig. 11).

La investigación realizada ha permitido establecer las siguientes conclusiones ${ }^{27}$ :

1. Se confirma la existencia de más de 50 esqueletos humanos en el fondo del pozo vertical a $30 \mathrm{~m}$ de profundidad que habrían sido arrojados desde el exterior.

2. Al menos existen dos episodios separados por una gruesa capa de cal.

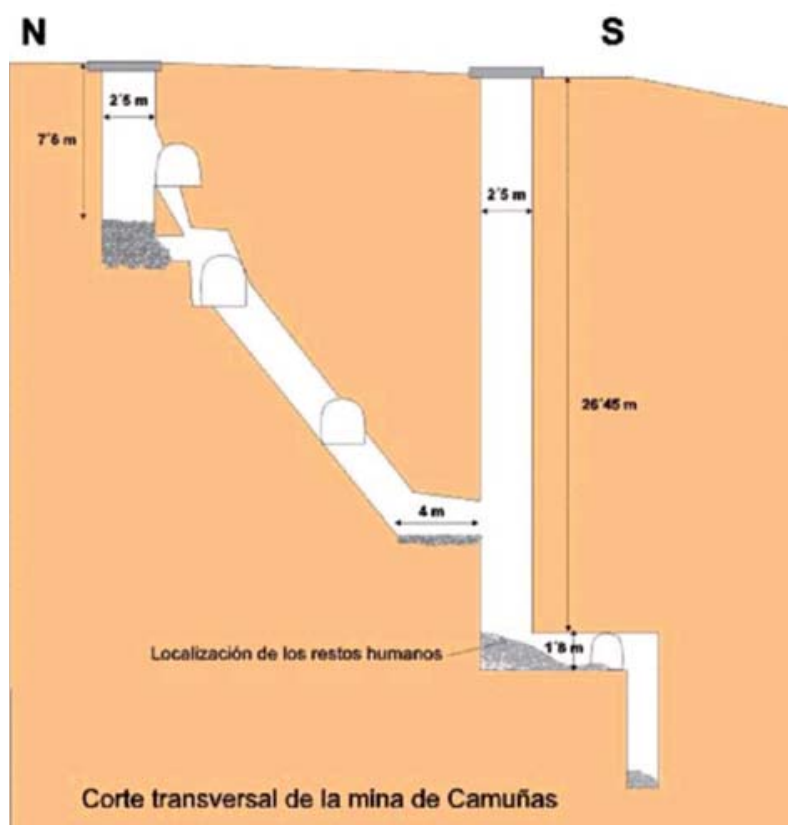

Fig. 9. Representación del pozo y lugar de los restos humanos. / Section of the mine shaft and position of the human remains.

3. Desde el punto de vista médico legal, las muertes pueden calificarse como violentas de tipo homicida siendo evidente la existencia de lesiones por arma de fuego en alguno de los casos que han sido apreciadas in situ.

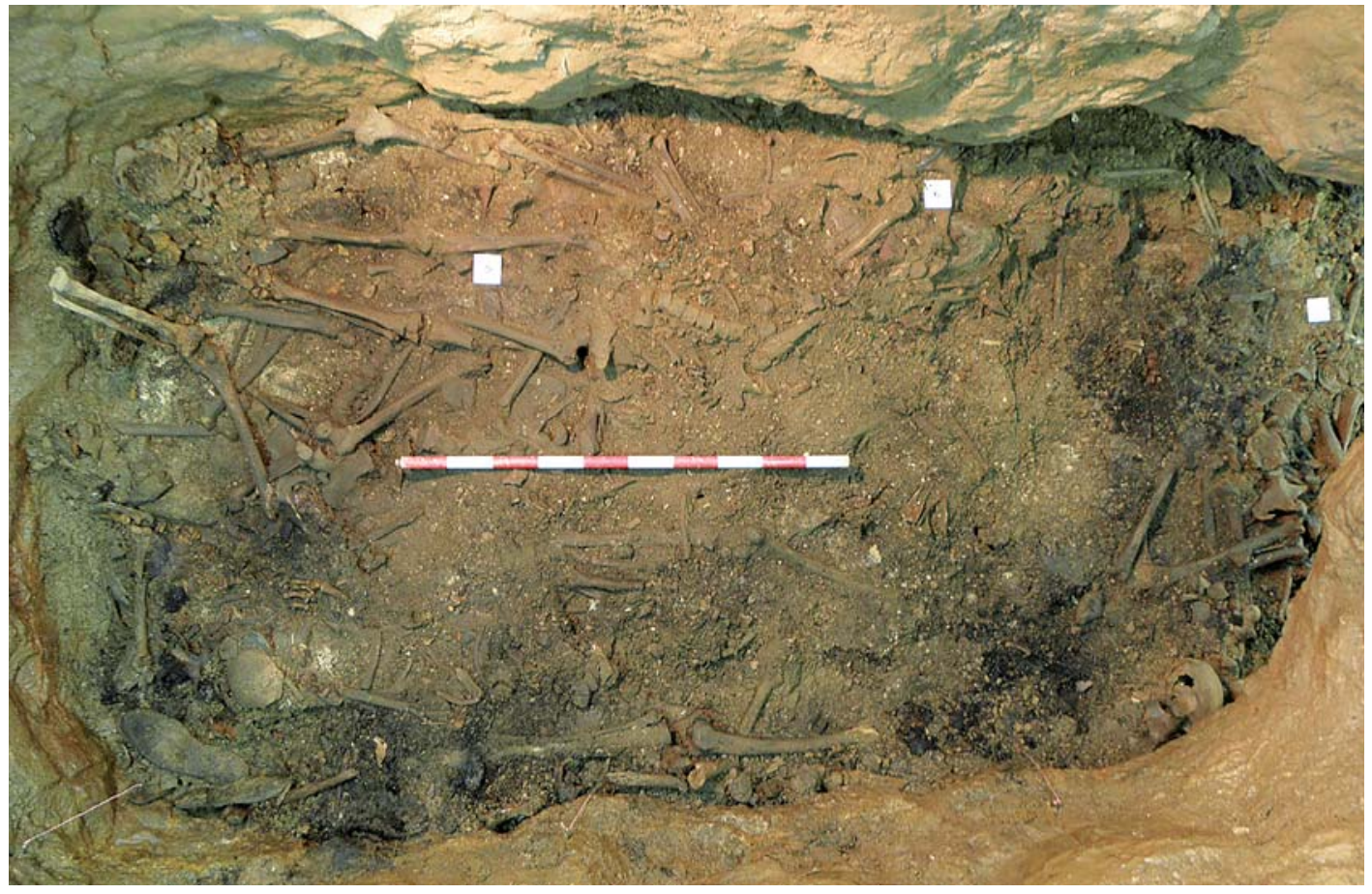

Fig. 10. Estado del fondo del pozo de Camuñas una vez retirada la tierra acumulada. / The base of the Camuñas shaft after removing the earth that had accumulated.

\footnotetext{
${ }^{27}$ Existe informe de 201 páginas de fecha 6 de mayo de 2009 (Archivo Sociedad de Ciencias Aranzadi).
} 


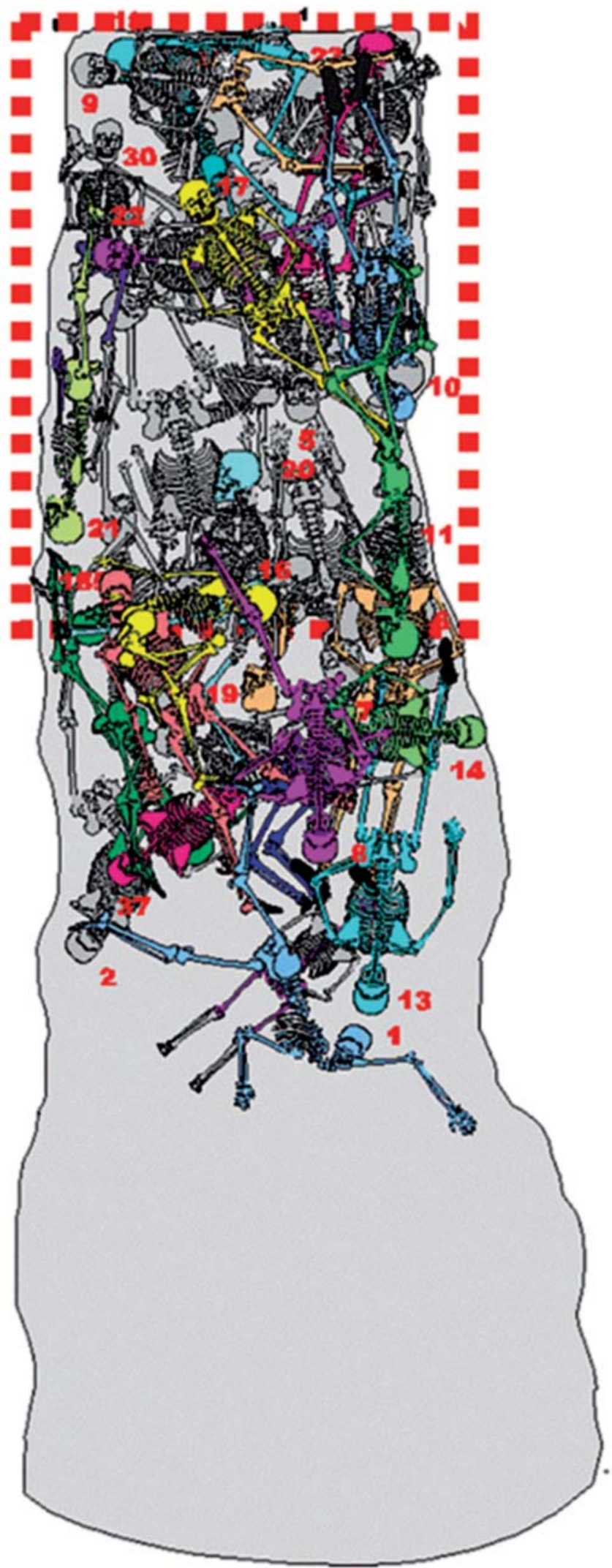

Fig. 11. Plano de la acumulación de individuos visualizados en el pozo y galería de Camuñas. El área delimitada en rojo se corresponde al pie del pozo. / Plan of the accumulation of individuals seen in the shaft and passage. The area marked in red represents the base of the shaft.
4. Las evidencias existentes del caso se ajustan a las versiones conocidas de los hechos, esto es, la muerte violenta de las personas que fueron arrojadas al pozo durante la Guerra Civil que posteriormente fue incendiado, siendo intencionadamente sepultados los cadáveres con cal y varias toneladas de tierra.

\section{POZO-MINA EL SALAMANCO CHICO (La Parra, Badajoz)}

El pozo se encuentra situado y debidamente protegido en una ladera de suave pendiente en la inmediata proximidad a los edificios de la finca ganadera de EI Salamanca Chico, bajo el camino de Villalba, a la altura del kilómetro 53,5 de la carretera 432 Badajoz-Sevilla. Las

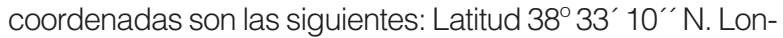
gitud 60 33' 17"' W. UTM: Uso 29. X 713.080. Y 4.270.064.

A solicitud de Dña. Isabel Perera, nieta del desaparecido Nicolás Martín Tejada y por mediación de D. Cayetano Ibarra (Comisario de Memoria Histórica de la Junta de Extremadura), en fecha 14 de julio de 2012, realizamos una inspección del pozo minero situado en la finca ganadera de El Salamanco Chicho de la localidad de La Parra (Tierra de Barros, Badajoz)28.

Para tal efecto se solicitó y obtuvo el permiso necesario por parte del Sr. D. Manuel García Durán, propietario de la finca en donde se encuentra el pozo.

Por información recogida a través de testimonios, consta que en ese lugar fueron arrojados en 1936 varios cadáveres como consecuencia de la represión ejercida en la comarca por partidarios de los sublevados franquistas contra los republicanos.

Previamente, en mayo de 2012 se realizó por parte de Condorgeoradar una inspección mediante el empleo de una cámara que fue introducida por la vertical del pozo y hasta el fondo del mismo en el nivel de inundación con una profundidad de $30 \mathrm{~m}$.

Contando con estos antecedentes y con el fin de comprobar la veracidad de la posible existencia de restos humanos en su interior, se plantea esta nueva inspección con descenso al pozo en donde tomamos imágenes fotográficas y videográficas.

28Para la realización de esta tarea se constituyó un equipo coordinado por Cayetano Ibarra (Comisario de Memoria Histórica de la Junta de Extremadura) e Isabel Perera Martín (Familiar) y en el que se integraron Fco. Etxeberria (Profesor Titular de Medicina Forense, Universidad del País Vasco), Lourdes Herrasti (Licenciada en Geografía e Historia, Sociedad de Ciencias Aranzadi), Tito Agirre (Sociedad de Ciencias Aranzadi), Luis Avial (Condorgeoradar) y Kelvin Mendoza (Condorge oradar). Asimismo se hallaban presentes las siguientes personas: Manual García Durán (Propietario de la finca). José Manuel Corbacho Palacios (Abogado y Presidente de la ARMH de Extremadura). Carmelo González Pérez (Familiar y vecino de Santa Marta). Ana Mª Guzmán Martín (Nieta de desaparecido y vecina de Badajoz). José Luis Guzmán Martín (Nieto de desaparecido y vecino de Feria). José González Pérez (Familiar y vecino de Santa Marta). José Angel Becerra Pérez. (La Parra). Loli Lagar González (La Parra). Existe informe específico de 34 páginas (Archivo Sociedad de Ciencias Aranzadi). 
Tal y como hemos señalado, en la mañana del día 14 de julio de 2012 acondicionamos el pozo mediante cuerdas de escalada y un torno eléctrico con cable de acero. Asimismo colocamos iluminación con suministro eléctrico desde el exterior alimentado por un generador. Previamente durante varios días y mediante una sonda de funcionamiento automático, se procede a la extracción del agua que se acumula en el interior del pozo. La lámina de agua se presenta a los $17 \mathrm{~m}$ de profundidad. El agua extraída se acumuló en un estanque inmediato a la fosa para su debido aprovechamiento. En cualquier caso todavía existía una cantidad de agua en el fondo (1'5 m) que tuvimos que extraer mediante la sonda con el fin de inspeccionar adecuadamente el suelo firme bajo el agua. Finalizada la exploración del pozo y galerías laterales, explicamos a todos los presentes el resultado de la intervención retirando todos los elementos instalados.

El pozo presenta una profundidad vertical de $30 \mathrm{~m}$. Se trata de una explotación minera que presenta, además, dos galerías laterales de desarrollo horizontal a mitad de su recorrido. La obra se realizó en fecha que no podemos determinar y para ello se excavó con barrena la roca de forma muy semejante a las obras de minería siguiendo patrones fijos en las medidas que son uniformes. De hecho, el pozo es rectangular de 2,80 m por 1,50 m en el tramo final hacia el fondo con alguna variación principalmente en la parte más alta del mismo o de acceso en donde es más amplio. En cualquier caso su acceso se encuentra rematado por una obra reciente con ladrillo abovedado y un tubo vertical de hormigón a través del cual se accede en los primeros $3 \mathrm{~m}$ desde el exterior. El fondo del pozo es irregular y está colmatado por abundancia de piedras de todos los tamaños y algunos bloques de hormigón que se han caído al realizar la obra. Asimismo en el fondo se encuentra la cadena de canjilones de hierro de la noria de extracción de agua que existió en tiempo anterior. Ambas circunstancias impiden ver el suelo original del pozo que debe situarse más abajo bajo este escombro.

Tal y como hemos señalado, existen dos galerías laterales que arrancan desde la vertical del pozo a $15 \mathrm{~m}$ y a 19,60 m. La primera de ellas parece haberse realizado a favor de una veta o grieta de extracción minera con desarrollo horizontal por donde es posible transitar hasta una distancia superior a los $6 \mathrm{~m}$. La segunda presenta mayor amplitud de entrada desde el pozo y se sitúa a 19,60 m de profundidad. Presenta forma de T ya que a los $4 \mathrm{~m}$ de desarrollo se abre en dos direcciones. A la derecha presenta un desarrollo horizontal de unos 20 m y es muy homogénea en sus formas. Desde el techo y paredes brota agua que escurre hasta el suelo y se canaliza de forma natural hasta el pozo en donde se acumula como si fuera una cisterna. A la izquierda la galería tiene un desarrollo de unos $10 \mathrm{~m}$. En el suelo de ambas galerías se acumula un limo muy fino de color amarillo con piedras sueltas de distinto tamaño. Asimismo hay algunas tablas de madera muy degradada y restos faunísticos de distintos animales, principalmente de cerdo, así como algunos plásticos de sacos de fertilizantes. Todo ello se ha debido caer al pozo y se ha acumulado en esta galería que marca el nivel de agua hasta esta cota por simple inundación por la escorrentía de las paredes. En su conjunto, pozo y galerías laterales son muy estables y no existe riesgo alguno de derrumbe ya que han sido realizados en una roca masiva muy firme.

Justo en el borde de entrada de esta galería localizamos en superficie tres huesos humanos que no fueron extraídos:

1. Fémur derecho parcialmente cubierto de limo. Por el tamaño de la cabeza femoral se puede interpretar que pertenece a un individuo masculino.

2. Escápula derecha parcialmente cubierta de limo. Presenta un ribete osteofítico en la cavidad glenoidea y por ello cabe suponer que pertenece a un individuo de edad adulta madura.

3. Esternón con foramen esternal (variedad anatómica que presenta hasta el $5 \%$ de la población) y fusión del apéndice xifoides y algunas calcificaciones de los cartílagos costales lo que permite suponer que pertenece a una persona de edad adulta madura.

El hallazgo de tres huesos humanos permite confirmar que en este pozo fueron arrojadas varias personas durante de Guerra Civil de conformidad a la hipótesis planteada ${ }^{29}$. El pozo y sus galerías laterales son en realidad una cisterna llena de agua cuya lámina se sitúa a 17 m de profundidad que ha sido empleada para su extracción y aprovechamiento durante distintas épocas.

Es razonable considerar que cuando fueron arrojados los cadáveres en 1936, estos se irían al fondo del pozo hasta la cota de $30 \mathrm{~m}$ (Fig. 12). Pero como consecuencia de la putrefacción y los gases propios de este efecto, los cuerpos subirían por flotabilidad hasta la superficie del agua que coincide con la cota de las galerías horizontales (17 m). De este modo, al menos uno de los cuerpos debió quedar retenido en la galería en parte de sus estructuras esqueléticas cuando ya en descomposición volverían a descender para ocupar el fondo definitivamente.

Posteriormente, el dispositivo de canjilones para la extracción del agua cayó al fondo y se sitúa sobre los restos humanos que han podido acumularse en ese lugar.

Como conclusión, se confirma la existencia de restos humanos y es posible que el fondo del pozo acumule más huesos pertenecientes a un número indeterminado de personas que fueron asesinadas en los municipios de La Parra y Feria, algunas de las cuales fueron arrojadas en este lugar 30

\footnotetext{
${ }^{29}$ La represión y las victimas que se produjeron en esta comarca puede consultarse en ESPINOSA (2003).

${ }^{30}$ En la inmediata proximidad de la boca del pozo localizamos una vaina de fusil Mauser que queda en manos del Sr. Cayetano Ibarra.
} 


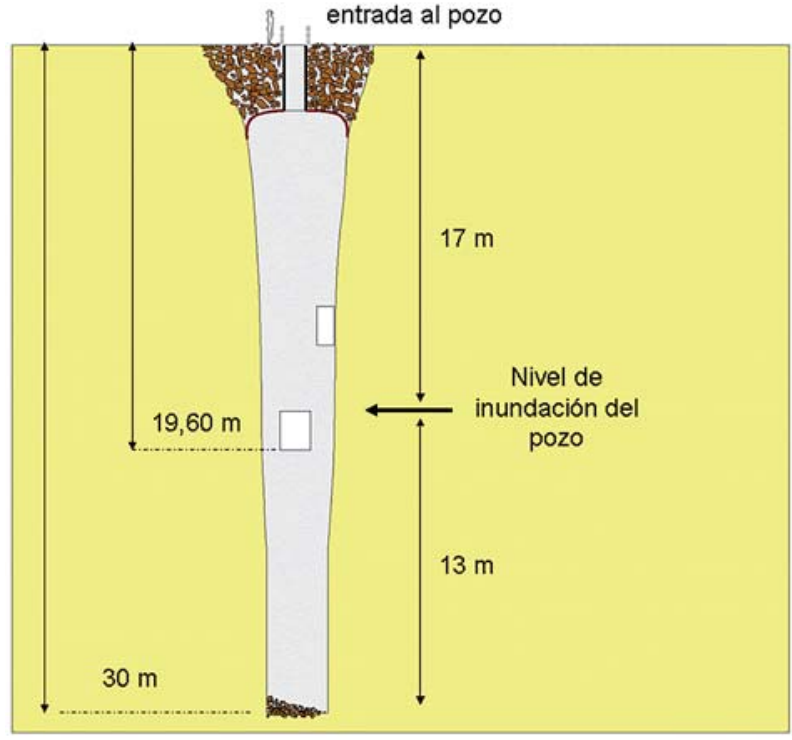

Fig. 12. Corte longitudinal del pozo El Salamanco Chico. / Section of El Salamanca Chico mine shaft.

\section{CALERO DE COVARRUBIAS} (Covarrubias, Burgos)

Los enterramientos se realizaron en el fondo de un calero situado entre las localidades de Covarrubias y Hortigüela (Burgos), por debajo de la carretera BU-905 y en la inmediata proximidad del río Arlanza. Para el enterramiento de los cuerpos se había aprovechado un calero de 3'30 m de diámetro y de 3 a 4 m de profundidad, situado en una ladera de fuerte pendiente caracterizada por un pinar con abundante vegetación. Coordenadas: Latitud $42^{\circ} 2$ ' 39" Norte. Longitud $3^{\circ} 28^{\prime} 18^{\prime \prime}$ Oeste. UTM: X 460.945 / Y 4.654.892.

A solicitud de D. José $\mathrm{M}^{a}$ Rojas, en representación de los familiares y por mediación de la Asociación para la Recuperación de la Memoria Histórica, en julio de 2005 llevamos a cabo la exhumación ${ }^{31}$ de ocho cuerpos esqueletizados como parte de la colaboración que venimos prestando a distintas asociaciones que vienen trabajando por la recuperación del olvido de las muchas personas desaparecidas, fusiladas y ejecutadas durante los trágicos episodios de la Guerra Civil española de 1936 a 1939. Esta actividad se lleva a cabo contando con el conocimiento de las autoridades de Burgos, esto es, el Juzgado de Instrucción de Lerma y la Subdelegación del Gobierno.

El plan seguido fue el siguiente: en la mañana del día 1 de julio de 2005 se reunió el grupo de trabajo en Cova- rrubias comenzando las tareas sobre la 12 de la mañana en el lugar en donde se encontraba la fosa. En este acto se explicó a los familiares allí presentes el plan de actuación para los días siguientes, referente a la excavación arqueológica y la recuperación de los restos que se dio por finalizada a las 14'30 horas del día 2.

Tras ubicar el espacio con sus correspondientes coordenadas cartesianas y limitados por la pared redondeada del calero, se realizó la excavación de toda la tierra circundante a los esqueletos para establecer una correcta individualización de cada uno de ellos que finalmente fueron extraídos separadamente comenzando por el último de los inhumados (Individuo 01).

El fondo de la calera se caracterizaba por presentar grandes piedras que habrían sido arrojadas al interior desde la ladera periférica. Al mismo tiempo existían cenizas y cal que formaban una costra muy dura en los primeros tramos del sedimento. En cualquier caso, los restos aparecieron a profundidades no superiores a los $50 \mathrm{~cm}$ en un plano inclinado en justa correspondencia con la sedimentación existente en el fondo del calero. Los restos humanos se encontraban en conexión anatómica con cierta superposición (Fig. 13 y Fig. 14). La base sobre la que se encontraban los restos se caracterizaba por una mayor concentración de raíces de la cubierta vegetal.

\section{Conclusiones:}

1. Las inhumaciones se realizaron en el fondo de un calero circular en donde fueron arrojados los cuerpos siendo desigualmente cubiertos con tierra y piedras.

2. El estado de conservación de los esqueletos es bueno como consecuencia de la protección de la tierra arcillosa con cenizas y cal a esa profundidad y no han sido removidos a lo largo del tiempo.

3. En las tareas de exhumación fueron recuperados los restos esqueléticos de un total de ocho personas, todas ellas masculinas de edad adulta, de conformidad a los criterios antropológicos estándar.

4. Todos ellos tienen el cráneo fracturado como consecuencia de disparos por arma de fuego que se pueden interpretar con sus respectivas trayectorias. El lugar topográfico en el que predominan los disparos es en la parte posterior del cráneo (fig. 15). Estas lesiones son la causa fundamental de la muerte que puede calificarse de violenta homicida en todos los casos.

5. En dos casos se constatan además otras lesiones traumáticas por arma de fuego en áreas distintas del cráneo.

\footnotetext{
${ }^{31}$ Promueven: familiares de los fusilados con el apoyo de la Asociación para la Recuperación de la Memoria Histórica. Coordinador: José Mª Rojas (ARMH). Arqueología: Javier Ortiz Lejarza, dirección arqueológica (Licenciado en Geografía e Historia, Sociedad de Ciencias Aranzadi). Jimi Jiménez (Licenciado en Geografía e Historia, Sociedad de Ciencias Aranzadi). Antropología y patología forense: Fco. Etxeberria (Profesor Titular de Medicina Legal y Forense, Universidad del País Vasco). Lourdes Herrasti (Licenciada en Geografía e Historia Dpto. de Antropología Sociedad de Ciencias Aranzadi). Borja Aguinagalde (Estudiante de $6^{\circ}$ de Medicina, Universidad del País Vasco). Otros técnicos: Igone Etxeberria (Fotografía y vídeo, Sociedad de Ciencias Aranzadi). Raquel Romero (Testimonios, Sociedad de Ciencias Aranzadi). José Bandres Lasa (Ayudante, Sociedad de Ciencias Aranzadi). Colaboradores y voluntarios: José Ma Rojas, Angel Velasco, Fernando García Hernando, Serafín Mansilla, Gonzalo Martínez Arranz y Rosa Ma Ríos Monge. Existe informe específico con descripción individualizada de cada esqueleto y relación de las víctimas de 103 páginas de fecha 26 de noviembre de 2005. Ver: http://www.sc.ehu.es/scrwwwsr/MedicinaLegal/covarrubias/Informe\%20exhumacion\%20Covarrubias.htm
} 


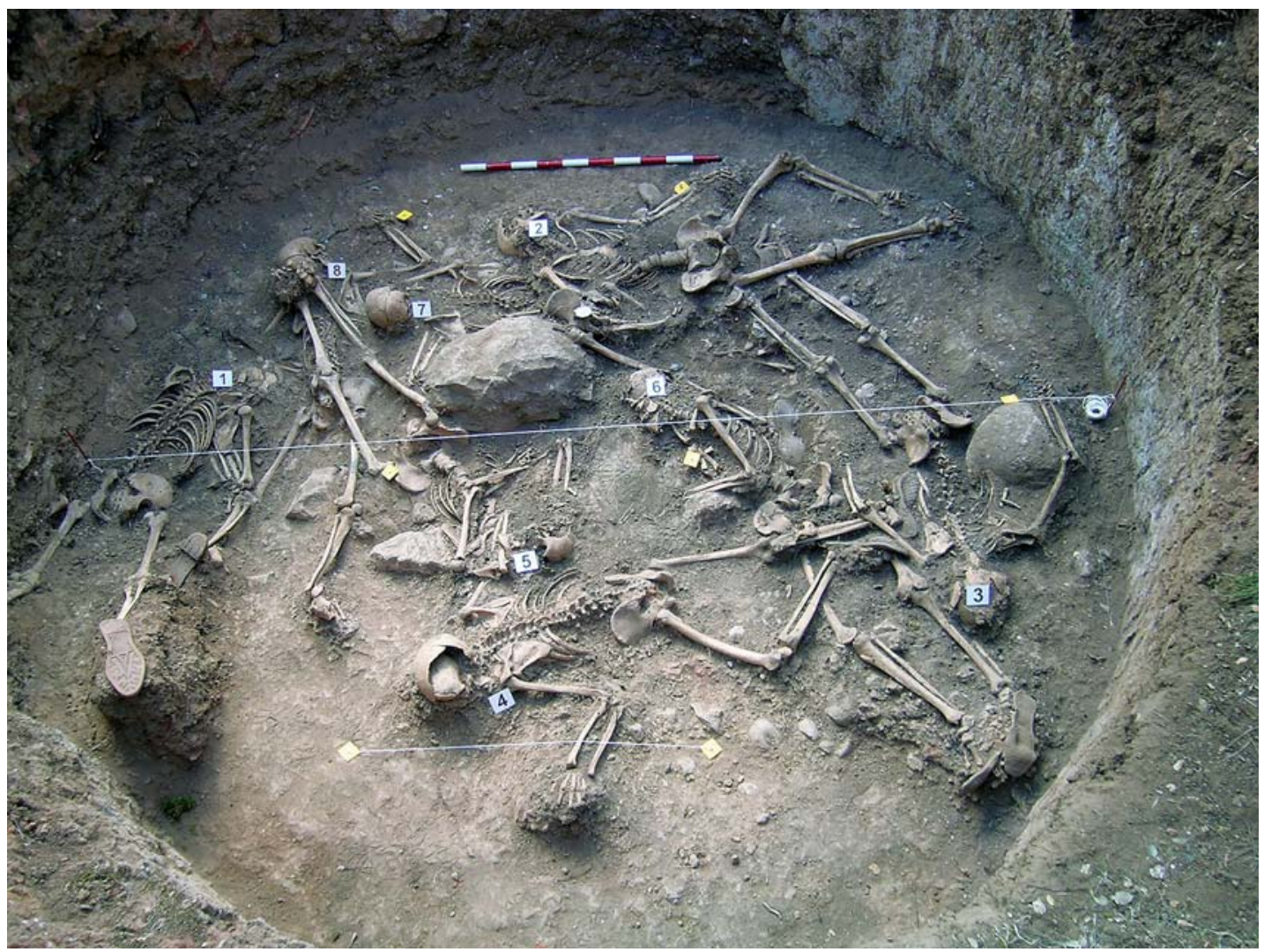

Fig. 13. Distribución de los esqueletos en el fondo de la calera de Covarrubias antes de su extracción definitiva. / Distribution of the skeletons at the base of Covarrubias lime-kiln before their definitive exhumation.

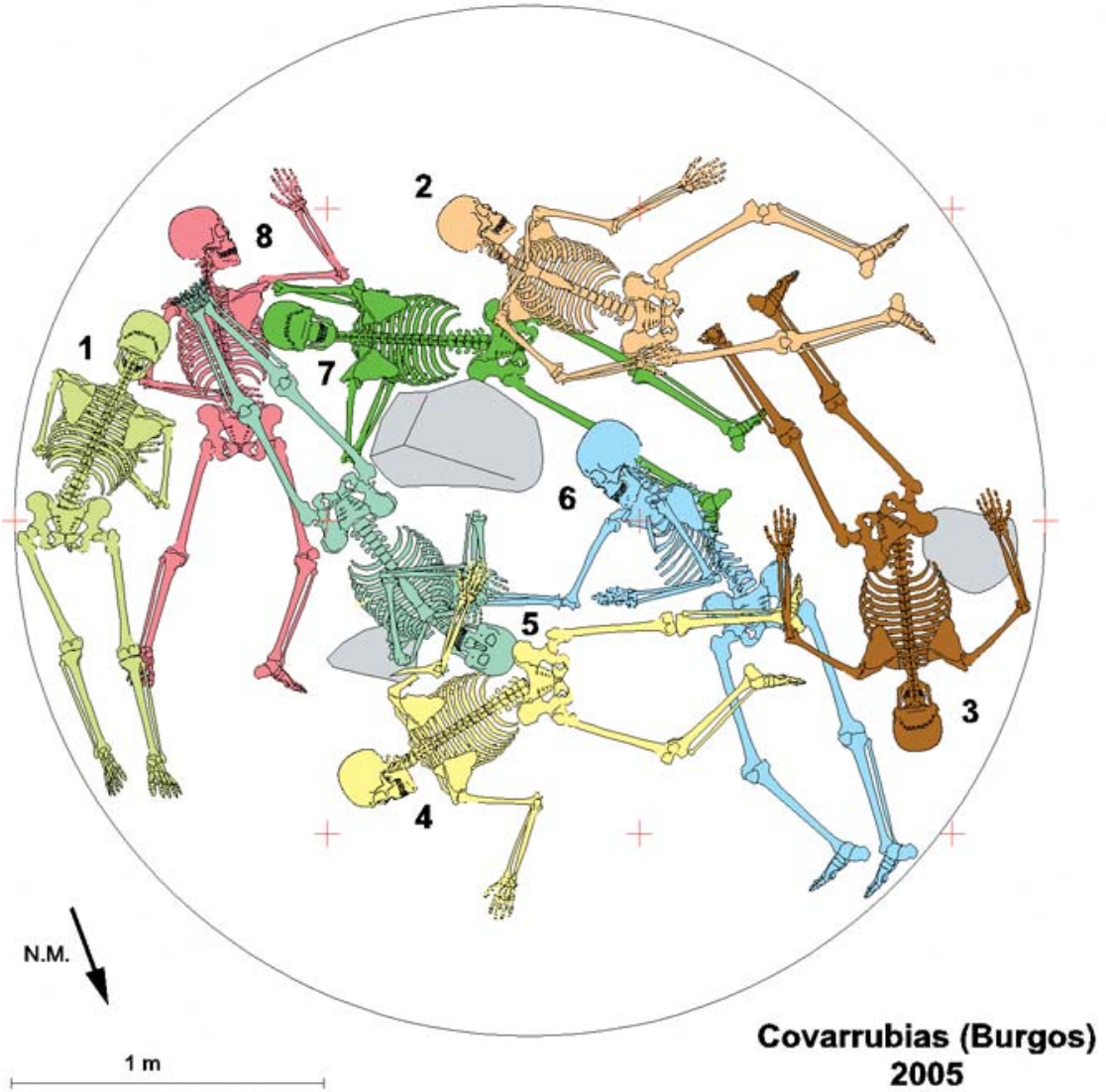

Fig. 14. Distribución de los restos en el fondo del calero. Distribution of the remains in the bottom of the lime-kiln. 


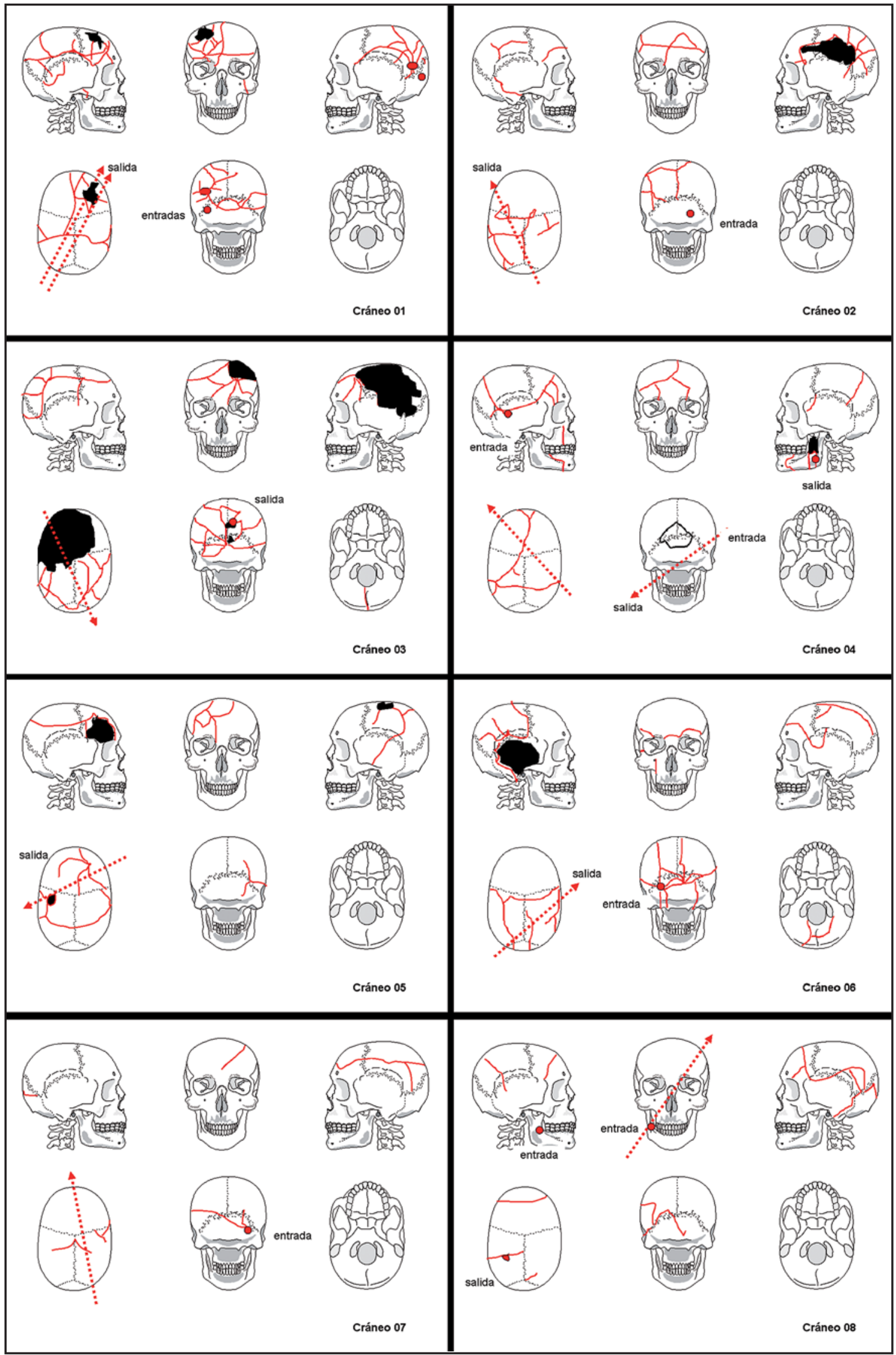

Fig. 15. Lesiones por arma de fuego y trayectorias en los cráneos de Covarrubias. / Firearm wounds and trajectories in the skulls from 
6. Se han recuperado dos proyectiles de arma de fuego correspondientes a pistolas de distinto calibre (7 y 11 $\mathrm{mm}$ ) (Individuos 1 y 5).

7. Las evidencias recuperadas y el análisis de conjunto permiten una interpretación de los hechos que concuerda fielmente con las versiones previamente recogidas a través de testimonios, esto es el asesinato y posterior desaparición de estas personas en 1936.

\section{BODEGA PEÑA TEJADA (Medina del Campo, Valladolid)}

A solicitud de D. Félix Huerta Llorente, en fecha $07-$ 08-2012 realizamos la visita a la finca en donde se localiza una bodega en desuso en donde consta fueron enterradas varias personas asesinadas como consecuencia de la represión vivida en la comarca en 1936. Acompañados por el propietario de la finca, Sr. D. Antonio García y su hijo, Sr. D. Juan Antonio García, realizamos una inspección del lugar llamado "Peña Tejada" al Suroeste de la carretera A6 y a unos 1200 m en línea recta, a la altura del kilómetro 164 en el municipio de Medina del Campo.

Se trata de un amplio terreno de cultivo para cereal que respeta en superficie el área (de 49 m de largo por 32 de ancho) que debe ocupar el espacio de la bodega (galerías) y en donde en su tiempo hubo una construcción de vivienda y una era. Coordenadas geográficas, longitud $41^{\circ} 21^{\prime} 5^{\prime \prime} \mathrm{N}$, latitud 4 58' 20”'W. UTM: X 335.002, Y 4.579.655, Z 783.

Por información facilitada por D. Antonio García, parece que en el interior de la bodega permanecen los restos humanos de personas que fueron arrojadas. A lo largo de los últimos años son varias las personas y asociaciones de memoria histórica que han mostrado interés por los hechos ocurridos en este lugar.

Sobre el terreno de la parcela no cultivada de aspecto cuadrangular de $49 \mathrm{~m}$ de largo y $32 \mathrm{~m}$ de ancho, se identifican ladrillos y fragmentos de teja que deben corresponder a la antigua construcción existente en el lugar. Asimismo hay un pequeño árbol y arbustos. No se encuentra roturado ante el riesgo de hundimiento del conjunto por la existencia de las galerías inferiores de magnitud desconocida.

El lugar exacto de la entrada a la bodega no se puede interpretar ya que fue sellado y en todo caso debe encontrarse al borde del camino de acceso al lugar. Por el contrario si son visibles en la superficie del terreno dos puntos que corresponden a respiraderos de la bodega que en los últimos años se han deteriorado y hundido.

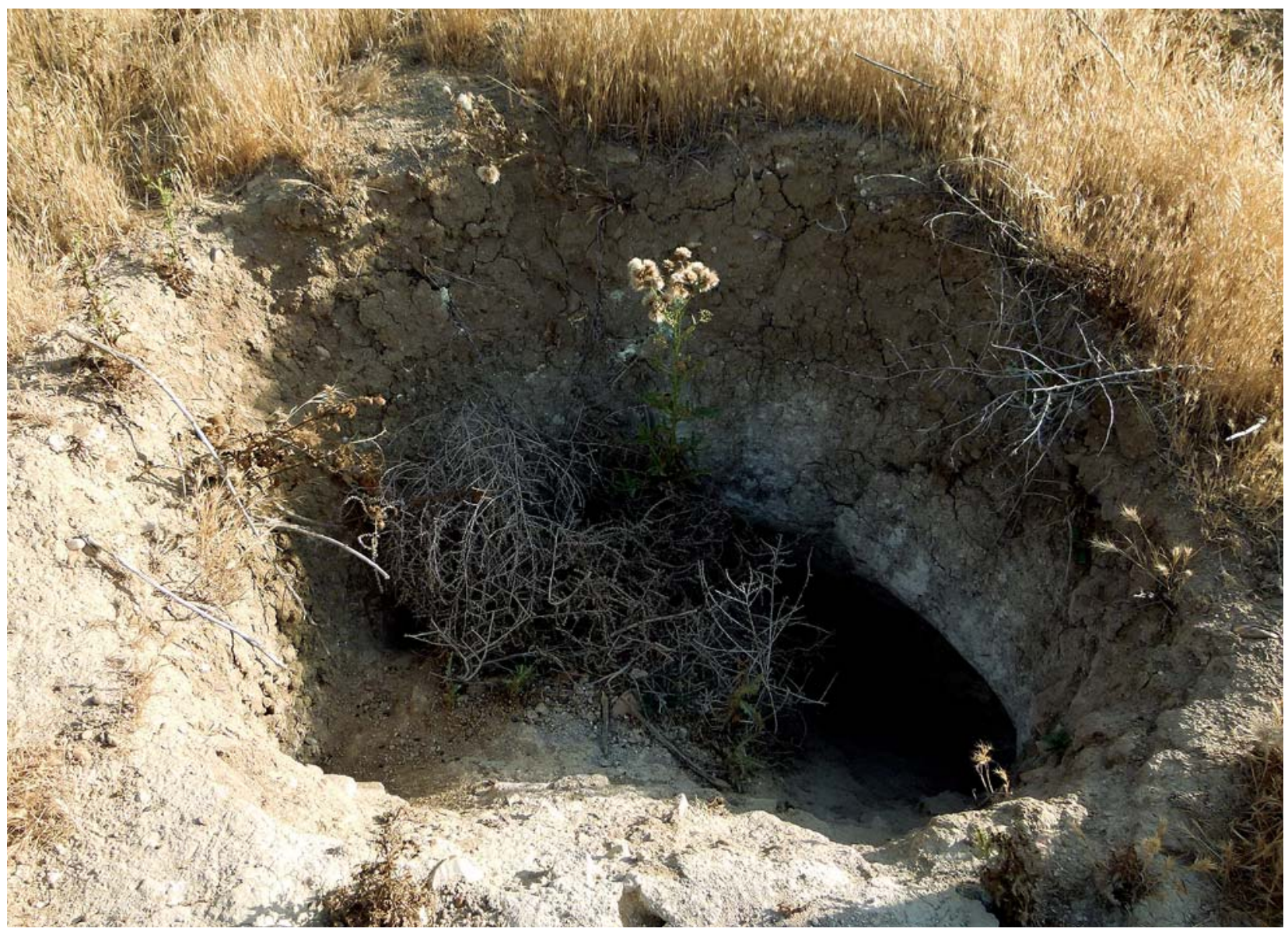

Fig. 16. Aspecto del respiradero de la bodega parcialmente tapado por derrumbe. / Wine-cellar ventilation shaft partially blocked by a collapse. 
En concreto, el más alejado del camino de acceso y de la entrada a la bodega, se encuentra colmatado con tierra intencionadamente ya que representaba un peligro en las labores agrícolas de superficie. Por ello destaca en el lugar como un abultamiento de tierra de más de 2 $\mathrm{m}$ de diámetro. En su proximidad hay otro respiradero hundido que presenta una rampa de tierra que desciende casi verticalmente al fondo hasta una distancia imposible de determinar y que puede superar los $6 \mathrm{~m}$ (Fig. 16). Estos respiraderos y otros que pudieran existir en origen, son pozos verticales que actualmente se encuentran colmatados de tierra.

\section{3.- CONCLUSIONES}

La recuperación de los restos humanos pertenecientes a las víctimas de la Guerra Civil es una tarea siempre compleja que requiere de técnicas especializadas desarrolladas desde el ámbito de la arqueología con una metodología contrastada a nivel internacional.

Estas mismas técnicas aplicadas a pozos artificiales y cavidades naturales se hacen aún más necesarias y a menudo requieren el diseño específico de recursos adaptados a cada caso por la dificultad propia de esos lugares en donde la experiencia es muy escasa.

Condiciones de seguridad, iluminación y reducidos equipos humanos bien preparados, no obstante posibilitan la correcta exhumación de estos restos que a su vez se caracterizan por su enorme fragilidad y degradación específica como consecuencia de las especiales condiciones medioambientales.

Los ejemplos investigados hasta el momento demuestran que estos espacios fueron empleados para el ocultamiento y son verdaderos lugares de memoria.

\section{4.- AGRADECIMIENTOS}

Al Grupo de Espeleología Satorrak y al Grupo de Espeleología de la Sociedad Gorosti por su colaboración en la recuperación de estas evidencias y la sensibilidad que han mostrado en esta materia.

\section{5.- BIBLIOGRAFÍA}

\section{ALONSO CÍSTER, D.}

2008 Verano del 36. La fosa común de la Guerra Civil de los Llanos de Caudé (Teruel). 158 pp. Edit. Mira. Zaragoza.

CASTRO, L.

2006 Capital de la cruzada. Burgos durante la Guerra Civil. Edit. Crítica. 383 pp.

EGAÑA, I.

2009 Los crímenes de Franco en Euskal Herria, 1936-1940. Edit. Txalaparta.
ESPINOSA, F.

2003 La columna de la muerte. El avance del ejército franquista de Sevilla a Badajoz. Edit. Crítica 559 pp.

\section{ETXEBERRIA, F.}

2012 Exhumaciones contemporáneas en España: las fosas comunes de la Guerra Civil. Boletín Galego de Medicina Legal e Forense 18: 13-28. Verín.

\section{OBREGON, F}

2014 República, Guerra Civil y Posguerra en Espinosa de los Monteros y Merindades de Montija, Sotoscueva y Valdeporres (1931-1950). $320 \mathrm{pp}$.

PERAL, D. y CASADO, M.

2004 Rescate de lugares de memoria. Experiencia en la mina de Valdihuelo (Badajoz): estudio antropológico forense y paleopatológico. En: Memoria histórica y guerra civil: represión en Extremadura. Julian Chaves (Coord.). Diputación de Badajoz.

PERAL, D.; FIGUERO, Mª J. y SANCHEZ, J.A.

2010 Paleopatología de las fosas de la Guerra Civil española en Extremadura: 2003-2008. Edit. @becedario. 329 pp.

PLANA, P.

1978 Informe de los trabajos de levantamiento del cadáver hallado en el Torcón de Cueva Burgos (Término Municipal de Contreras). Kaite 1: 63-70

SANTESTEBAN, I. y ACAZ, C.

1992 Catálogo Espeleológico de Navarra. Gobierno de Navarra. $604 \mathrm{pp}$

SERRULLA, F. y ETXEBERRIA F.

1995 Estudio antropológico forense de los restos óseos hallados en Cova Arcoia (O Courel, Lugo). Boletin Galego de Medicina Legal e Forense 1: 9-13. Descargable en www.agmf.es

VAZQUEZ, M

2003 O Courel. Editorial Galaxia.

V.V.A.A.

2004 Navarra 1936. De la Esperanza al Terror. Edit. Altaffaylla. $855 \mathrm{pp}$.

2008 Asociación Pozo Grajero. La memoria del Grajero. Edit. Servipres. 319 pp.

2012 Antropología forense de la Guerra Civil española. Boletín Galego de Medicina Legal e Forense 18. Descargable en http://www.agmf.es/boletines/boletin18.pdf 